\section{Marriage and fertility} in Tianjin, China: Fifty years of transition

Burton Pasternak
PAPERS

OF THE

EAST-WEST POPULATION INSTITUTE

NUMBER 99 JULY 1986

\section{王}

EAST-WEST CENTER HONOLULU, HAWAII 
PAPERS OF THE EAST-WEST POPULATION INSTITUTE, published about eight times a year, facilitate early dissemination of research findings and policyrelevant reports on the populations of Asia, the Pacific, and the United States. Cost per copy, $\$ 3$.

NOTE TO CONTRIBUTORS: The Population Institute considers unsolicited as well as commissioned manuscripts for the Paper Series. Appropriate topics are demographic trends and estimation, fertility and family structure, economic development and human resources, urbanization and migration, and population policies and programs. All manuscripts are reviewed, In selecting manuscripts for publication, the Institute considers quality of scholarship and usefulness to public officials and other professionals in the field of population; it also seeks contributions reflecting diverse cultural and disciplinary perspectives on population. The series can accommodate articles not necessarily suited for journals because of unusual length or treatment of subject. All copy must be typed double-spaced. For additional information on manuscript preparation, write to Editor, Paper Series.

\section{OTHER SERIAL PUBLICATIONS OF THE EAST-WEST POPULATION INSTITUTE}

Working Papers are circulated for comment and to inform interested colleagues about work in progress at the East-West Population Institute. They are intended to complement evidence of completed work as reflected in Papers of the EastWest Population Institute and the Reprint Series. \$1 per copy.

Reprint Series brings selected articles originating from Institute research but published elsewhere to the attention of population specialists who might not otherwise see them. Single copies available upon request.

Asian and Pacific Census Forum is a quarterly periodical reporting on census, vital registration, and population survey activities in Asia and the Pacific. The Forum contains technical articles on a range of topics related to demographic measurement, and reviews of new publications in the field. Issued in August, November, February, and May. Annual subscription rate, \$5.

Serial publications except Working Papers are available without charge to libraries serving population specialists and to professionals and scholars in the field of population. Requests describing the nature of the research or program and the intended use of the publications should be addressed to: Publication Sales and Distribution, East-West Center. 


\title{
Marriage and fertility in Tianjin, China: Fifty years of transition
}

\author{
Burton Pasternak
}

Number $99 \bullet$ July 1986 
BURTON PASTERNAK is Professor of Anthropology at Hunter College and Graduate Center, City University of New York.

\section{Library of Congress Cataloging-in-Publication Data}

Pasternak, Burton.

Marriage and fertility in Tianjin, China.

(Papers of the East-West Population Institute ;

no. 99 (July 1986))

Bibliography: $p$.

1. Marriage-China-Tientsin. 2. Fertility, Human-

China-Tientsin. 3. Family-China-Tientsin.

4. Tientsin (China)-Social conditions. I. Title.

II. Series: Papers of the East-West Population Institute; no. 99.

HQ684.P38 $1986 \quad 306^{\prime} .0951^{\prime} 15 \quad 86-16515$

ISBN 0-86638-080-9 


\section{CONTENTS}

Preface vii

Abstract 1

Methodology 3

Patterns of migration 5

Population structure 7

Education, occupation, and income: narrowing the gender gap 11

Education 12

Employment 13

Income 16

Marriage custom and practice 19

Universality of and age at marriage 19

Selecting a spouse 24

Marriage rituals 28

Postmarital residence 31

Household form 36

Intrafamilial relations: monetary contributions 36

Fertility and the demographic transition 38

Effect of increased access to education 38

Effect of female participation in the work force 39

Patterns of fertility change 41

Pre-Liberation Tianjin: context for low fertility 46

Tianjin after Liberation: political controls on fertility 50

Conclusions 65

References 69 


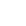$$
\text { . }
$$ 


\section{FIGURES AND TABLES}

\section{Figures}

1. Proportion of women from Tianjin, by year married: Red Sky, December 19817

2. Age-sex pyramid: Red Sky, December 19818

3. Mean age at marriage, by year married: Red Sky, 1931-80 22

4. Proportion of couples who met on their own or without formal introduction, by year married: Red Sky, 1936-81 25

5. Postmarital residence, by year married: Red Sky, 1936-79 32

6. Total fertility: Red Sky, 1936-81 44

7. Infant mortality: Red Sky, 1933-79 44

8. Total marital fertility: Red Sky, 1936-81 45

9. Age-specific marital fertility, by birth cohort: Red Sky 52

10. Breastfeeding rate and duration, by mother's age: Red Sky 57

11. Children in Red Sky, by sibling order and year of birth: 1949-81 61

12. Total fertility: Red Sky and urban China, 1950-81 64

\section{Tables}

1. Educational level attained, by age and sex: Red Sky, December $1981 \quad 14$

2. Population employed, by age and sex: Red Sky, December $1981 \quad 15$

3. Type of employment, by age and sex: Red Sky, December $1981 \quad 17$

4. Income inequality: Red Sky, urban China, and developing societies 19

5. Monthly wages, by type of employment and sex: Red Sky, December 198120

6. Population ever married, by age and sex: Red Sky, 1981; China, $1982 \quad 21$

7. Time (in months) acquainted at marriage, by year married: Red Sky, December $1981 \quad 26$

8. Type of engagement ceremony, by year of marriage: Red Sky, pre-1949 to post-1975 28

9. Type of bridewealth, by year of marriage: Red Sky, December 198129

10. Type of dowry, by year of marriage: Red Sky, December 198130 
11. Parity of women of ages 35 and over, by highest educational level attained: Red Sky, December 198140

12. Parity of women of ages 35 and over, by type of employment: Red Sky, December $1981 \quad 41$

13. Fertility, by five-year intervals: Red Sky, 1937-81 43

14. Duration-specific legitimate fertility, by years married and birth cohort (first marriage): Red Sky, December 198153

15. Age-specific fertility in first marriage among women $30-44$ years of age, by birth cohort and age at marriage: Red Sky, December 198154

16. Duration-specific legitimate fertility during first four years of marriage, by age at marriage and birth cohort: Red Sky, December $1981 \quad 55$

17. Mean birth intervals of women in first marriage, by birth cohort: Red Sky, December 198156

18. Parity of women, by year married: Red Sky, pre-1926 to 1981 


\section{PREFACE}

This study is based on fieldwork conducted in Tianjin from September 1981 to January 1982. Although the data were collected in collaboration with Pan Naigu (Chinese Academy of Social Sciences) and Pan Yunkeng (Tianjin Academy of Social Sciences), and while Pan Naigu and Wang Ching (Beijing Food Research Bureau) assisted during various stages of data processing, I alone am responsible for the analysis of the data. I am grateful to Wang Ching and to Martin $\mathrm{K}$. Whyte for suggestions offered on an earlier version of this manuscript. A debt of gratitude is due the Institute of Sociology, Chinese Academy of Social Sciences; the Tianjin Municipal Government; and the Tianjin Academy of Social Sciences for sponsorship and support in the field. Finally, I would like to thank the generous people of Red Sky who endured with patience and kindness my probing into their personal lives and history.

Fieldwork in Tianjin was conducted under grants of the Committee for Scholarly Communication with the People's Republic of China, and the National Science Foundation. Funds for various phases of the data analysis were provided by the National Science Foundation and by the Research Foundation of the City University of New York. 


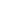$$
\text { . }
$$ 
ABSTRACT This is a report of research conducted in Tianjin, People's Republic of China (September 1981 to January 1982), the objective of which was to describe and analyze changes in family structure, marriage, patterns of postmarital residence, and fertility in a neighborhood of factory workers, over a period of fifty years. The data, derived from a combination of interviews, questionnaires, and documentary research, indicate how demographic data can provide an objective indicator and measure of social and political change.

Many of the social and economic changes that took place during the modernization of presently developed societies also took place in Tianjin. Mortality quickly and precipitously declined, for example. Access to education greatly expanded and women were drawn into the labor force. Marriage and reproductive life were delayed and the young acquired greater control over, and responsibility for, the arrangement of their own marriages. Spouses more commonly moved away from their parents at marriage, and as a result families became simpler. In a purely economic sense raising children became more costly and less rewarding, and, as the theory of demographic transition would have us expect, fertility declined.

But modernization theory and the model of demographic transition do not anticipate the fertility transformations that actually occurred in Tianjin. Although most of the fertility-depressing correlates of modernization emerged and fertility did decline, the pattern of change indicates that fertility was at least as responsive to political shifts as to changes predictable simply on the basis of what occurred during the modernization of developed societies. The paper suggests that it may be more useful to begin with the demographic pattern, and to use it to signal potentially important economic, political, or social causes, than to begin with specific social changes, assuming that they invariably have a powerful and consistent effect on fertility.

Some results of China's 1982 census and national fertility survey have already appeared in Chinese and English, and scholars have begun to analyze the data available. The data upon which this analysis is based are, however, of a different sort. This is a report of research conducted in Tianjin (Tientsin) ${ }^{1}$ municipality from September 1981 to January 1982 . The study focused on the relationship between social forms and institutions on the one hand, and demographic behavior on the other. The more specific objective was to describe and analyze, diachronically, family structure and patterns of postmarital residence, marriage, and fertility in a neighborhood of factory workers. The study examined, over time, the way families have adjusted to a variety of constraints, such as those imposed by occupation, income, housing availability, natural disasters, political turmoil, and systematic family limitation.

1. Pinyin romanization of Chinese placenames is used in this paper. The Wade-Giles equivalent normally appears in parentheses after the first mention of a place. 
The data are derived from a combination of interviews, questionnaires, and documentary research. They are unusual in that they provide a small window through which to view change over a period of nearly fifty years in a single neighborhood of factory workers in Tianjin. The data are also unusual because they provide information about a segment of China's population about which little is known. Ethnographic data on urban Chinese families, either in mainland China or on Taiwan, are rare; this study is a beginning in determining what is and is not representative, how much variation there is, and how much change has taken place and why.

From simple, modest industrial beginnings in the 1920s and 1930s, Tianjin went on to become one of China's most important modern, industrial cities. The most dramatic development occurred after 1949, when industry flourished and expanded and population grew rapidly. A loose urban structure was replaced by one that was integrated to an unprecedented degree. Tianjin was no longer a temporary stopping place for desperate, impoverished males from the countryside, but rather the permanent home of people born and raised in the city. It became a city of families carefully organized into stable neighborhoods. What were the social, economic, and demographic correlates of this rapid modernization? Many of the changes that have taken place during the modernization of presently developed societies also took place in Tianjin. Mortality quickly and precipitously declined, for example. Access to education greatly expanded and women were drawn into the labor force. Marriage and reproductive life were delayed and young couples acquired greater control over, and responsibility for, the arrangement of their own marriages. Spouses more commonly moved away from their parents at marriage and, as a result, families became simpler. In a purely economic sense raising children became more costly and less rewarding, and, as the theory of demographic transition would have us expect, fertility declined.

On the other hand, the analysis reinforces the view that caution must be exercised in anticipating or interpreting changes in developing societies in terms of models based on the experience of already developed societies. While most of the fertility-depressing correlates of modernization emerged in Tianjin and while fertility did decline, the pattern of change suggests that fertility was at least as responsive to political shifts as to changes that are predictable simply on the basis of what occurred during the modernization of developed societies. We are often told that political, economic, and other policy shifts have had substantial social consequences in China. This paper will indicate how demographic data, in this particular case data on fertility, can provide an objective indicator and measure of social and political change. 


\section{METHODOLOGY}

The study was based on fieldwork conducted in two neighborhoods of Tianjin. Because there are no objective standards with which to assess the typicality or atypicality of any Chinese urban neighborhood, it seemed worthwhile simply to document a case for later comparison. I selected a site not unusual in terms of income, education, population structure, and occupation, and then reconstructed patterns of marriage and fertility over a period of several decades through interviews and the use of questionnaires. I made a concerted effort to ensure a universe with social integrity in the sense that information gathered would refer to one or two complete neighborhoods. In the end I was able to include all households and individuals in a single neighborhood, Red Sky. Whenever I describe Red Sky as a "neighborhood," therefore, my observations are based on a universe rather than on a sample. In addition, because the cohort of women of ages 55 and over (women whose reproductive lives peaked before Liberation in 1949) was relatively small, I included all such women, along with their coresident daughters and daughters-in-law, who were living in an adjoining neighborhood. When my focus is on the characteristics of individuals rather than on the characteristics of the neighborhood, therefore, the inclusion of these people makes it possible to enlarge the data base.

From the outset, my research was seriously restricted because of a moratorium against anthropological and sociological fieldwork by foreigners that was then in effect in China. My presence was therefore a matter of considerable sensitivity and concern to Chinese sponsors at various levels. Although my hosts were finally persuaded to meet my sampling requirements, they found it necessary to limit my inquiry to items and procedures agreed upon from the outset, and to structure the conditions of my stay so as to severely limit contact with the people of Red Sky. I was housed in a dormitory at Tianjin University, on the other side of the city, and was driven to and from Red Sky each morning and evening. I was allowed to conduct research only on the condition that I not travel the city on bicycle. Lunch was sent to my office from a nearby restaurant that was off limits to me. I usually took dinner in my room.

These precautions were in part intended to ensure my comfort and safety, as my hosts saw it, and in part to limit my dealings with the general population. Contact was further constrained by a requirement that all interviews be conducted in an office provided by the local government. I was not to visit people in their homes except under special circumstances and with advance notice. These were hardly optimal conditions for anthropological inquiry but, because I had designed the project anticipating such restrictions and because my objectives were limited, the constraints within which I had to function, while frustrating, were not ruinous. 
Upon my arrival in Tianjin, my hosts organized meetings at all administrative levels to permit me to explain my objectives, requirements, and procedures, and to elicit help. To achieve any measure of success I needed to ensure the support of personnel at each level and in each relevant work unit. I therefore made certain that everyone understood what I was doing, why I was doing it, and how I hoped to get the job done. After approving the project, local authorities instructed neighborhood representatives and small group leaders responsible for particular buildings to provide all assistance. In accordance with that mandate, neighborhood representatives scheduled interviews, and small group leaders delivered questionnaires.

I obtained information about the population in three ways. I interviewed all women of ages 55 and over. Before the interview each informant was asked to complete a questionnaire to familiarize her with the questions she would be asked during the interview and, if necessary, to enlist the help of others to fill memory gaps. Group leaders checked the questionnaires for completeness, paying special attention to anticipated problem areas. Questionnaires were delivered to me at least one day before each interview, providing a second opportunity to detect errors and omissions. I reviewed the questionnaires once again during the interviews, at which time each informant was asked to help complete a questionnaire for each daughterin-law and married daughter living in Tianjin.

Informants unable to come to my office were visited and interviewed in their apartments. A few people refused to be interviewed, and in these instances I either persuaded their daughters or daughters-in-law to provide needed information, or at least determined if they were unusual in important ways by consulting the household registry and by talking to neighbors and neighborhood representatives.

Since many households did not include women of ages 55 or over and since many women in their mid-30s lived in conjugal units (neolocality being the prevailing rule of residence), I extended my inquiry to include married women under age 55. It was impossible, however, to interview each of them because of restraints on time and because virtually all were factory workers on a three-shift schedule. The data on these women are therefore based entirely on questionnaires. Since the memories of the younger women were better than those of the older women, I do not think that this is a serious shortcoming. I used household registers to obtain data on households without married women.

At the completion of my information gathering, I had interviewed and collected questionnaires from 272 women of ages 55 and over (96 percent response). Another 312 questionnaires had been obtained from married women under age 55 ( 95 percent response), and I had an additional 242 questionnaires for married daughters and daughters-in-law, seventy-three 
of whom lived with the older informants. Information about households without married women was taken directly from household registers and corrected with the help of local authorities. In the analysis that follows I make use only of data pertaining to Red Sky households and to women living in Red Sky and its adjacent neighborhood. I have not included information obtained about daughters and daughters-in-law living elsewhere.

It was crucial to this research that the timing of events be as accurate as possible. The traditional Chinese manner of calculating age can throw ages off by one or two years because children are considered to be age 1 at birth, and another year is added at the New Year. This is particularly a problem in the case of older women. However, another Chinese tradition makes it possible to get around this difficulty. Each year is linked to one of twelve animals. Because the animals follow each other in a particular sequence, forming a twelve-year cycle, the knowledge of a person's yearof-birth animal makes it possible to pin down the year of birth. There is no comparable custom that would make it possible to fix the year of marriage, but neither is there a tradition that systematically generates error.

This study is based largely on retrospective data. Every effort was made to reduce the number of unreported births, miscarriages, and abortions. Informants were pressed about all birth intervals that seemed unusually long (more than two years). All efforts notwithstanding, however, there is still reason to believe that some births and miscarriages were not reported, as infant mortality rates seem low for the location. Although I do not present them in this paper, miscarriage rates also seem low. One consequence is that the fertility rates, particularly those for earlier periods, may slightly underestimate real rates. I will discuss this in more detail later.

\section{PATTERNS OF MIGRATION}

Red Sky is one of twenty-eight neighborhoods or "residents' committees" (Juminin Weiyuan Hui) in West Mountain Street, West River District, Tianjin City. In 1982 West River District administered a population of 501,152 (State Council Census Office 1983:6). According to local authorities, West Mountain Street, which covers an area of 72 square kilometers, had a population in 1981 of 68,699 in 18,286 households. The neighborhoods of West Mountain Street are relatively new. Before Liberation in 1949 the area was used for water drainage and "dumping corpses of the poor." After 1949, however, Tianjin developed rapidly and, from 1954, West Mountain Street was transformed; 172 state factories were built, along with some 900 tenement buildings. A business and service infrastructure emerged to meet the needs of the rapidly growing population.

Most of the inhabitants of West Mountain Street came either from other parts of the city or from the surrounding Hebei countryside. For the most 
part urban migrants were poor, often solitary, males in search of relief from exceptionally oppressive conditions in the rural areas. It was not uncommon for families with several sons to send one or more into the city to learn a marketable skill, or for husbands to leave their families to seek better opportunities in the city. Urban migration did not necessarily mean, though, either complete separation from family members in the rural areas or permanent residence in the city. The boundary between city and country was highly permeable; migrants often maintained roots in the country, returning during harvest, or to marry. They made their way back to the city when their labor became superfluous, when new opportunities opened up, or when natural disaster made life in the countryside more untenable than that in the city.

There were numerous migratory waves during the 1920s and 1930s, mainly the result of civil war, famine, and flood. More than 30,000 people fled the famine-stricken rural areas in the autumn of 1920, for example. In 1939 a flood precipitated a major migration, and even more people reportedly found their way to Tianjin during the spring of 1940 because earlier flood damage made it impossible to plant crops.

The largest wave of refugees came during the years of civil war that preceded Liberation; by mid-1948, refugees in Tianjin numbered about 100,000 (Hershatter 1982:413-14). Figure 1 provides evidence of this early massive migration to Tianjin. It reveals a sharp decline in the proportion of women now living in Red Sky whose families lived in Tianjin during the 1920s, when migration to the city was substantial. The proportion continued to decline gradually during the 1930s, and then abruptly at the time of the 1939 flood. The proportion of women from Tianjin rose gradually beginning with the early 1940s, and then precipitously from 1959. According to Kenneth Lieberthal, when the Chinese Communists took Tianjin in 1949:

[they] rapidly removed the most obvious signs of the chaos that had preceded liberation-the scattered soldiers, refugees from other areas, homeless persons from the suburbs, and so forth. . . . The Communists registered the over 22,000 students and landlords who had fled to Tientsin from the Northeast and sent them back to their native areas. They sent an additional 5,700 students and teachers from North China back to the countryside (Lieberthal 1980:31-32).

From 1959 Chinese policy systematically operated against migration to the city. Strict measures, such as rationing and control of travel, work, and housing, effectively stopped urban migration and forced many young city dwellers back to the country. The effectiveness of these measures is indicated in Figure 1 by a precipitous rise in the proportion of women from Tianjin after 1958. 


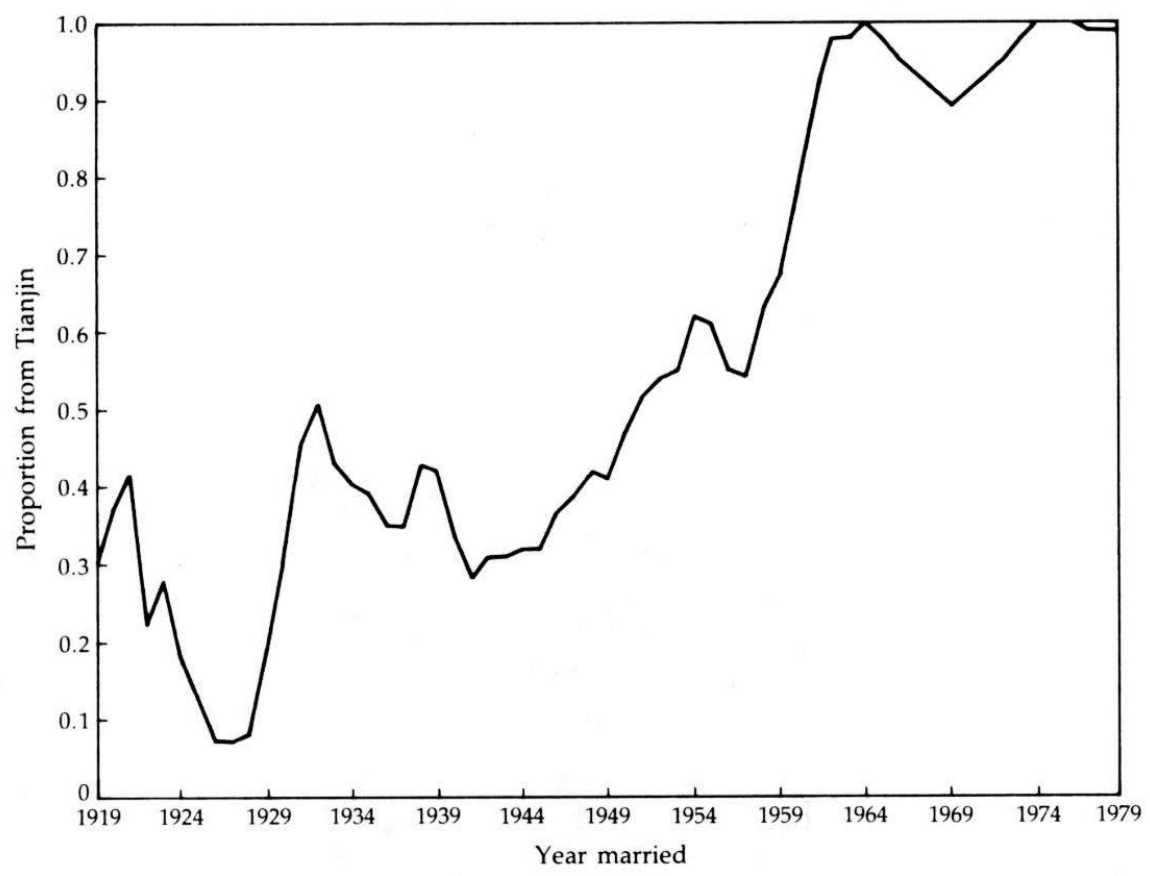

Figure 1. Proportion of women from Tianjin, by year married: Red Sky, December 1981

(five-year moving average)

\section{POPULATION STRUCTURE}

In December 1981 the population of Red Sky numbered 1,831, 952 males and 879 females. Red Sky's age-sex pyramid for that time (Figure 2) reveals two marked constrictions, one from about 1937 to 1952, the other since 1962. The first is, in part at least, a result of catastrophic conditions in Tianjin from the time Japanese troops occupied and dominated the city and surrounding countryside in 1937 through the years of World War II. During this period of starvation, shortage, inflation, and spousal separation, fertility plummeted. The situation was exacerbated by the particularly devastating flood in 1939. Some Red Sky residents claim that, in response to these difficult conditions, urban people often intentionally avoided conception. Because avoidance was not parity-specific, however, fertility curves for the period resemble those of a natural fertility population characterized by a low level of fertility. The second constriction in the age-sex pyramid is largely the result of systematic and increasingly effective family planning efforts since 1962. 


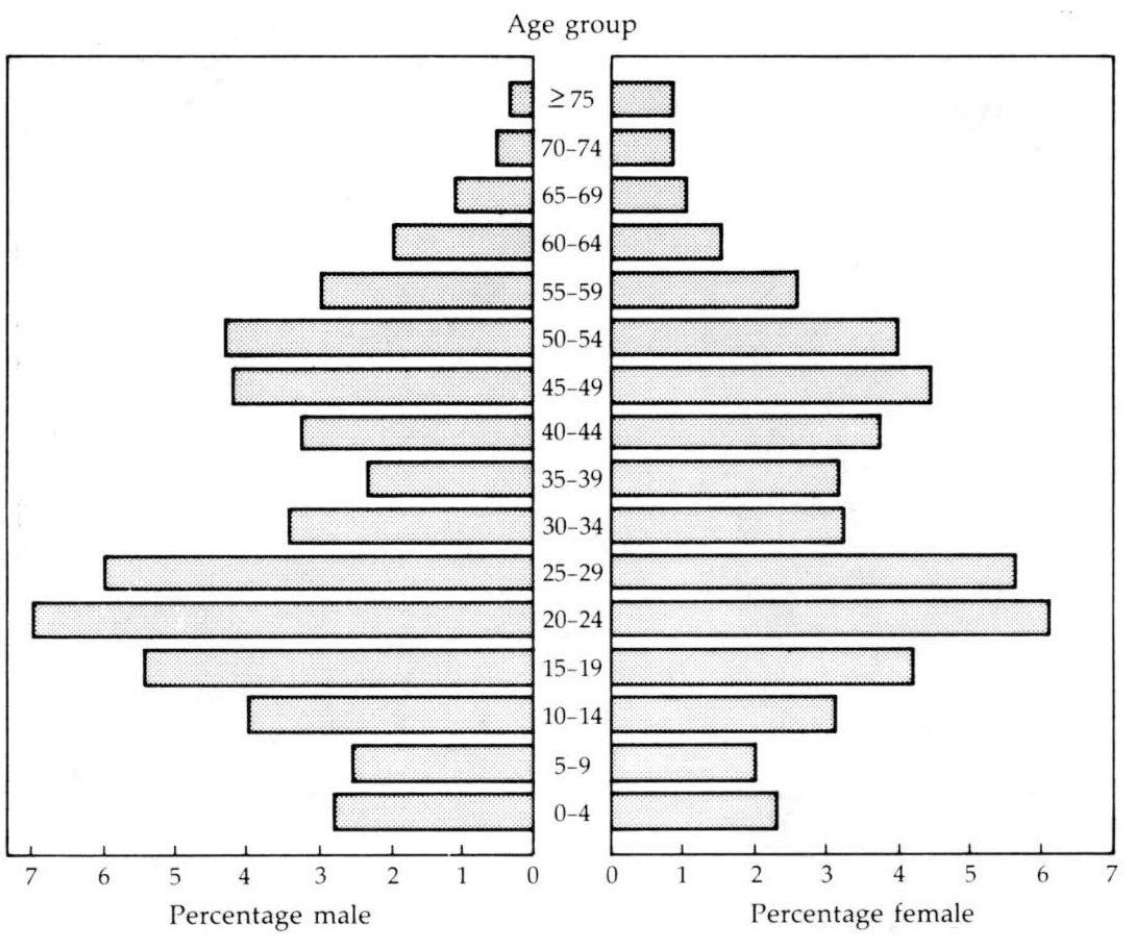

Figure 2. Age-sex pyramid: Red Sky, December 1981

It is possible that the two bulges in Red Sky's age-sex pyramid were less the result of periodic disasters than of the way the community was settled. Opened up about twenty-five years before the time of the survey, the area may have attracted a disproportionate number of young married or single people not already attached to existing factories and housing. These people and their children might account for the two bulges in Figure 2. Although the nature of settlement may have exaggerated these bulges, comparison with data from the 1982 Chinese Five Cities Project reveals similarly shaped age-sex pyramids even for well-established urban neighborhoods (Five Cities Family Research Project Group 1985:336-43).

Red Sky's masculinity ratio in December 1981 was 108.3, which is close to that of urban China generally; the sample census conducted in 1982 indicates an urban ratio of 107.6 (State Statistical Bureau 1983:276-77). One reason that has been suggested for China's relatively high masculinity ratio is that the population has become substantially younger since 1949. Since sex ratios at birth and among children to age 15 normally favor males, the overall masculinity ratio for a young population is also likely to favor males (Liu Chunmei and Li Zhu 1984:154-55). 
The 1981 data from Red Sky do not, however, indicate an especially young population. The age-dependency ratio was 27 percent. Most of the population (79 percent) was in the nondependent age category, 15-64; only 17 percent of Red Sky's population was under age 15. Calculations using urban figures from the sample census indicate that the age-dependency ratio was a bit lower in Red Sky than in urban China generally, where it was 31 percent; 26 percent of China's urban population was under age 15 (State Statistical Bureau 1983:276-83).

To what extent is the low age-dependency ratio in Red Sky a new phenomenon? Although I have no hard data on age dependency either in Red Sky or in Tianjin for periods prior to my research, there are early data from Danggu (Tangku), a town some 30 miles to the southeast. According to a 1926 survey of workers' families at the Jiu Da (Chiu Ta) Salt Refinery located there, the age-dependency ratio was similar to that in contemporary Red Sky (Lin 1928:56). To compare dependency in Red Sky with that in Danggu it is necessary to modify the dependency measure to use age 60 as the start of the oldest age group rather than the more conventional age 65. The overall age-dependency ratio in Danggu was then 35.3 percent compared with 25.4 in Red Sky, the child-dependency ratio was 24.7 percent compared with 25.4, and the aged-dependency ratio was 10.5 percent compared with 11.9. Since the data pertain only to workers living near the refinery with their families, and since the majority were young males living in the plant dormitory, the age-dependency ratio for the town was probably lower, with fewer elderly people and still fewer children.

While Chinese cities are not all the same, the figures for Red Sky are also similar to those from Beijing (Gamble 1921:416). The age-dependency ratio for Beijing in 1917 was 28 percent, which is almost the same as my figure of 27 percent. The child-dependency component for Beijing was 22 percent, and the aged-dependency ratio was 5 percent. Both figures are remarkably close to those for Red Sky (22 percent and 6 percent, respectively).

In short, China's cities may have long been characterized by a high proportion of individuals in potentially productive age categories. In the past this was likely the result of high mortality rates and of wives and children remaining in the rural areas, both contributing factors to a low childdependency ratio. Today, however, the low child-dependency ratio is instead a consequence of unusually effective family planning. Similarly, older people currently constitute a small proportion of Red Sky's population not because of high mortality or because they return to the countryside when they grow old, but because massive immigration of young people prior to the late 1950s, together with periods of high fertility, resulted in a relatively large cohort of young adults. 
Rather than reflecting the young age of the population, the high masculinity ratio characteristic of contemporary Red Sky may in part reflect fluctuations that are a function of working with small populations. But if the difference between number of males and females is real, then it may be less a function of the population's youth than the product of migration patterns. Before 1949 and for some time thereafter, the population of China's cities generally contained a disproportionate number of single men, or married men with families in the countryside. According to various sources, sex ratios were far more favorable to men in pre-1949 Tianjin than they are at present; the sex ratio was 141.5 in 1936 (China Yearbook 1937-45:2), 135 in 1939 (Tianjin Municipality Executive Office 1939:n.p.), 137 in 1947 (Tianjin Municipal Statistics Bureau 1948), and 133.4 in 1948 (China Yearbook 1950:17). Women and children often remained in the countryside with the husbands' parents, as urban life was felt to be unsuitable for women and children. Women who lived in the city very often did so in response to poverty, and those who worked were surely doing so for this reason since outside work under male foremen automaticaly placed a woman's virtue in question.

There is reason to suspect that female infanticide may also have contributed to the sex imbalance, as birth statistics indicate a disproportionate number of males. In 1939, for example, the sex ratio at birth was 112 (Tianjin Municipality Executive Office 1939). Although more males were reported born, females "attained parity" in death, as Hershatter put it; women constituted 50 percent of all deaths in 1939 although they accounted for only 43 percent of the population (Hershatter 1982:362; see also Tianjin Municipality Executive Office 1939). Data from Sidney Gamble's 1917 Beijing survey also indicate a higher death rate for females at every age. Although women constituted 46 percent of Beijing's population, the overall female death rate was 33.2 compared with 21.6 for males (Gamble 1921:417-18).

On the other hand, the preponderance of males in Tianjin's pre-1949 population cannot be accounted for simply by differences in mortality. Among workers, at least, it was mainly the result of a pattern of migration that brought more males than females to the city in search of work. Even today there are men who have moved to the city without their families, for different reasons, though, than in the past (Goldstein 1985:44-46). Regulations governing migration to China's major cities in place since the late 1950s limited urban migration, but they also made it difficult for rural men assigned work in the city to bring their families with them. It may be significant that, if we exclude from our calculation thirty-four Red Sky men who were living alone, the masculinity ratio in Red Sky drops to only 104.4, which is quite normal. 
Taken by itself, then, Red Sky's masculinity ratio does not necessarily suggest an unusually young population, any current tampering with sex ratios in the form of female infanticide, or even a disparity resulting from a disproportionate number of female deaths at later ages-according to the census results for Tianjin's West District, the crude death rate in 1982 was 5.6 per thousand for both males and females (State Council Census Office 1983:1:12-13, 3:29). ${ }^{2}$ Rather, it is a function of the dramatic effect of urban migration on population characteristics and structure in the area.

\section{EDUCATION, OCCUPATION, AND INCOME: NARROWING THE GENDER GAP}

A man in China is usually subjected to the domination of three systems of authority: (1) the system of the state (political authority), ranging from the national, provincial and county government to the township government; (2) the system of the clan (clan authority), ranging from the central and branch ancestral temples to the head of the household; and (3) the system of gods and spirits (theocratic authority), including the system of the nether world ranging from the King of Hell to the city gods and local deities, and that of supernatural beings ranging from the Emperor of Heaven to all kinds of gods and spirits. As to women, apart from being dominated by the three systems mentioned above, they are further dominated by men (the authority of the husband). These four kinds of authority-political authority, clan authority, theocratic authority and the authority of the husband-represent the whole ideology and institution of feudalism and patriarchy, and are the four great cords that have bound the Chinese people and particularly the peasants (Mao 1954:45).

The preferred and most common postmarital residence pattern in traditional Chinese contexts, and in rural China today, is patrilocal. The expectation is that sons will remain with their parents at marriage while daughters will leave to join their husbands. Property passes in the male line, and the relationship between parents and children is emphasized more than that between spouses. As care of the aged is entirely in the hands of sons, male children are strongly preferred. The common saying is, "boys are precious, girls useless." Daughters are useless in the sense that they are ultimately given to others-usually in other villages or neighborhoods-just as they reach productive age.

2. Calculations using figures gathered in the Five Cities Project reveal sex ratios more favorable to women than that in Tianjin; e.g., the masculinity ratios for Beijing, Shanghai, Nanking, and Chengdu ranged from 91.2 to 99.8 (Five Cities Family Research Project Group 1985:358). Those ratios may actually underestimate the number of males, however, because researchers evidently did not include single men living in factory dormitories. 
The inclination in China has long been to temper or even to eliminate this patrilineal bias. Mao was certainly not the first to propose that China was laboring under a social system in need of complete overhaul. The notion has roots that go back at least to the second half of the nineteenth century, at the time of a violent Western intrusion. During the mid-nineteenth century the Taiping rebels spoke of fostering gender equality, and, during the so-called "100 days' reform" in 1898 , family reform was held to be essential to the modernization that would enable China to resist the foreigners and to assume a place in the community of modern states. After the last imperial dynasty, a great ideological ferment began that crystallized in the May Fourth Movement of 1919. The country's ills and decrepitude were blamed on the restraints of tradition and, in particular, on the traditional Chinese family and its extensions-lineage and clan. Intellectuals spoke of the need to create a "new society" in which marriage would be based on mutual attraction and love, and in which the individual would be liberated from the control of the family.

Although the intellectual roots of family reform antedate the Chinese Communists, the Communists were the first to effectively engineer major changes. It was Mao's position that the traditional Chinese family and its system of ideological and ritual props (like ancestor worship) constituted a kind of sociocultural disease. Mao and his colleagues were convinced that as long as there was no real freedom of marital choice and children were married early to satisfy familial rather than individual needs, as long as there was no freedom of divorce, as long as male prerogatives continued to be emphasized at the expense of female rights and privileges, and as long as women remained subjugated to their husbands and mothers-inlaw, China would suffer inefficiencies and nepotism, and therefore subjugation at the hands of barbarians.

The belief was that the family was part of a superstructure. To change family relations, therefore, the material foundations upon which the family was constructed-in particular, the nature of property relations-must be altered. Family reform in the countryside would inevitably result from agrarian reform. In the cities it would follow from changes highlighting the conjugal relationship. Neolocality would alleviate pressures and constraints imposed by the parental generation. Providing women with access to education and involving them in wage labor outside the home would presumably give them greater voice within the domestic sphere.

\section{Education}

The evidence from Red Sky indicates a remarkable expansion of access to education for women since Liberation. Although the data suggest a significant male advantage overall at each level of attainment, when they are 
broken down by age it is clear that the gender differences reflect historical rather than contemporary reality (Table 1). Educational access increased for both sexes, but especially for women. The gender difference is not significant at any level for people under age 40. Data from the Five Cities Project similarly indicate rapid improvement in women's education. A comparison of the education of husbands and wives by year married in three Shanghai localities and in one Nanking neighborhood shows substantial improvement in the relative status of women despite the fact that men still enjoy an advantage (Five Cities Family Research Project Group 1985:105, $149,179,203-4,361-69)$.

The data from Red Sky also show evidence of an interesting reduction in the proportion of residents attending college. The proportion of men and women of ages 30-39 who attended college was 7.5 percent, compared with 9.8 percent of those $40-49$. The percentage declined further to 2.2 in the age group $20-29$. The change is especially marked among men. Twenty percent of all men 40-49 attended college, but the percentages for men 30-39 and $20-29$ were only 7.4 and 2.0 respectively-a decline that is statistically significant. This reduction in college attendance was probably related to institutional disruption associated with the Cultural Revolution. From 1966 to 1972 all colleges were closed. Although they were reopened in 1973, academic entry standards were waived and the quality of instruction was poor until about 1976. This had little effect on the quality of education for individuals of ages $40-49$, but it did affect younger people. Those in the age group 30-39 at the time of the study either had no access to college or were limited to programs that provided inadequate academic training. People now in the age group 20-29 had to endure middle and high school training that was so deficient that, when university entrance examinations were reinstated in 1976, they were unable to compete successfully for available openings with people of ages $30-39$, who had at least obtained an adequate middle and high school background. The problem was certainly not specific to Tianjin. According to one neighborhood study for Shanghai, "the educational level declined among couples married after 1977. Most only achieved middle school (wives 71 percent, husbands. 50 percent), and only one wife attended college" (Five Cities Family Research Project Group 1985:106).

\section{Employment}

A breakdown of Tianjin's population in 1947 by sex and occupation indicates that 42 percent were employed, that most workers were male, and that the kinds of work done by men and women were not the same (Tianjin Municipal Statistics Bureau 1948). Only 10.8 percent of women were employed, compared with 65 percent of men. Women constituted 16 percent of the industrial labor force, 39 percent of the service sector, and 3 percent 
Table 1. Educational level attained, by age and sex: Red Sky, December 1981 (percentage)

\begin{tabular}{|c|c|c|c|c|c|c|c|c|}
\hline \multirow[b]{2}{*}{ Educational level } & \multicolumn{2}{|c|}{$<20$} & \multicolumn{2}{|c|}{$20-39$} & \multicolumn{2}{|c|}{$40-59$} & \multicolumn{2}{|c|}{$\geq 60$} \\
\hline & $\begin{array}{c}\text { Males } \\
(\mathrm{N}=266)\end{array}$ & $\begin{array}{l}\text { Females } \\
(\mathrm{N}=207)\end{array}$ & $\begin{array}{c}\text { Males } \\
(\mathrm{N}=334)\end{array}$ & $\begin{array}{l}\text { Females } \\
(\mathrm{N}=319)\end{array}$ & $\begin{array}{c}\text { Males } \\
(\mathrm{N}=259)\end{array}$ & $\begin{array}{l}\text { Females } \\
(\mathrm{N}=246)\end{array}$ & $\begin{array}{c}\text { Males } \\
(N=60)\end{array}$ & $\begin{array}{c}\text { Females } \\
(N=70)\end{array}$ \\
\hline All levels & 100 & 100 & 100 & 100 & 100 & 100 & 100 & 100 \\
\hline None & 28 & 26 & 1 & 1 & 2 & 29 & 7 & 76 \\
\hline Primary or higher & 72 & 74 & 99 & 99 & 98 & 71 & 93 & 24 \\
\hline Middle or higher & 46 & 49 & 96 & 96 & 69 & 39 & 58 & 3 \\
\hline High-vocational or higher & 24 & 23 & 37 & 40 & 35 & 16 & 28 & 1 \\
\hline College or university & $*$ & $\star$ & 4 & 4 & 14 & 3 & 3 & 1 \\
\hline
\end{tabular}

- Less than 1 percent. 
Table 2. Population employed, by age and sex: Red Sky, December 1981

\begin{tabular}{lrrrrr}
\hline & \multicolumn{2}{c}{ Males } & & \multicolumn{2}{c}{ Females } \\
\cline { 2 - 3 } \cline { 5 - 6 } Age group & No. & $\%$ & & No. & $\%$ \\
\hline $16-19$ & 95 & 43 & 65 & 35 \\
$20-29$ & 237 & 93 & & 214 & 92 \\
$30-39$ & 108 & 100 & & 115 & 97 \\
$40-49$ & 136 & 98 & & 147 & 82 \\
$50-59$ & 132 & 88 & & 117 & 49 \\
$60-64$ & 36 & 61 & 27 & 11 \\
$>64$ & 34 & 18 & 47 & 6 \\
\hline
\end{tabular}

of the commercial sector-the three sectors that most commonly employed women. Of males employed, 43 percent were in commerce, 30 percent in industry, and another 10 percent in communications and transportation. Of employed women, on the other hand, 11 percent were in commerce, 46 percent were in industry, and 27 percent in the service sector. Since 1949 the proportion employed among China's urban population has risen dramatically. In Tianjin alone, employment rose from 27 percent during the 1950s to 63 percent in 1979. Whyte and Parish propose that the decline in unemployment during the 1970s was, in part at least, the result of families having fewer children (Whyte and Parish 1984:37-38).

For Red Sky, occupational information is available for 1,821 people, or 98 percent of the population. As of December 1981, 64 percent were salaried, a percentage slightly lower than in other cities; data on proportion of family members employed available for five of eight urban localities surveyed indicate a range from 68 to 77 percent (Five Cities Family Research Project Group 1985:412). Of Red Sky's "working age" population (ages 16-59 for men and 16-54 for women, as defined in the sample census), 84 percent were employed ( 87 percent of working age men and 80 percent of women). Calculations based on figures for the entire municipality indicate a rate of 89 percent (98 percent of working age males and 79 percent of females) (State Statistical Bureau 1983: 306-7, 326-27). Working age males were therefore more fully employed in Red Sky than in Tianjin as a whole, but this could be because the figures for all Tianjin include suburban and rural people under municipal administration, populations that might well have higher male underemployment.

Table 2 indicates the degree to which the promise of full employment has been fulfilled in Red Sky. For ages 20-39, employment is close to universal for both sexes, but the sexes diverge thereafter. As in the past, males still constitute a significantly greater proportion of the work force. A large 
proportion of Red Sky's youngest and oldest workers are male-for several reasons. As jobs, like housing, are allocated by state agencies, men tend to be assigned work a bit sooner than women. Men also retire later; the recommended retirement age for men is 60 compared with 50 for women. In addition, many of Red Sky's older women never entered the work force, or worked for only short periods.

Most of the employed population of Red Sky consists of factory workers (Table 3). Next in number are office workers and those employed in the service sector. Only 3 percent of the work force, almost entirely older women, are employed by local (neighborhood-run) enterprises. Workers under age 40 vary little in type of employment except that men more commonly than women find work in the service sector. Gender differences are more striking, however, for older workers; men are more likely than women to be cadres and office workers, while women more often work in neighborhood collectives or in the service sector. Middle-aged men have a virtual monopoly over important administrative and white-collar jobs. From these data alone, though, it is difficult to know to what extent women are excluded from certain kinds of jobs simply because they are women, and to what extent their lack of representation is due to the fact that they entered the work force late, have little seniority and experience, and generally retire earlier than men.

Despite impressive improvement in levels of urban employment in China generally and in Tianjin in particular, unemployment continues to be a matter of concern, particularly as it affects the young. In 1981, 7 to 8 percent of Red Sky residents in their 20s had not yet been assigned work. The figure mirrors the 7 percent reported by Whyte and Parish for urban China during the early and mid-1970s (Whyte and Parish 1984:201).

\section{Income}

The findings of a recent neighborhood survey for Beijing indicate a positive correlation between level of education and wages for women of ages 41 or older (Five Cities Family Research Project Group 1985:48-49). The relationship is reversed for younger women, however, especially for those under age 30 . The explanation proposed is that, from 1949 to the mid-1970s, Chinese policy favored blue-collar over generally better educated whitecollar workers. The salary scale of white-collar workers was characterized by more steps with less difference between steps. White-collar workers also received fewer and less substantial bonuses. The result was that seniority generated income increments more slowly for such workers.

The data from Red Sky confirm a positive relationship between level of education attained and income for people of ages 60 and over. Although the results are ambiguous for residents of ages $30-59$, we do find the antici- 
Table 3. Type of employment, by age and sex: Red Sky, December 1981 (percentage)

\begin{tabular}{|c|c|c|c|c|c|c|c|c|}
\hline \multirow[b]{2}{*}{ Employment } & \multicolumn{2}{|c|}{$\leq 39$} & \multicolumn{2}{|c|}{$40-59$} & \multicolumn{2}{|c|}{$\geqq 60$} & \multicolumn{2}{|c|}{ All ages } \\
\hline & $\begin{array}{c}\text { Males } \\
(N=369)\end{array}$ & $\begin{array}{l}\text { Females } \\
(N=333)\end{array}$ & $\begin{array}{c}\text { Males } \\
(N=249)\end{array}$ & $\begin{array}{l}\text { Females } \\
(N=177)\end{array}$ & $\begin{array}{c}\text { Males } \\
(N=26)\end{array}$ & $\begin{array}{c}\text { Females } \\
(N=7)\end{array}$ & $\begin{array}{c}\text { Males } \\
(N=644)\end{array}$ & $\begin{array}{l}\text { Females } \\
(\mathrm{N}=517)\end{array}$ \\
\hline Local collective & 1 & 1 & - & 15 & - & 14 & 1 & 6 \\
\hline Service & 24 & 16 & 7 & 11 & 23 & 29 & 17 & 14 \\
\hline Industry & 57 & 58 & 34 & 42 & 23 & 14 & 47 & 52 \\
\hline Office & 14 & 17 & 25 & 20 & 19 & 14 & - 18 & 18 \\
\hline Cadre & - & - & 22 & 1 & 31 & 14 & 10 & 1 \\
\hline Technical or professional & 5 & 8 & 12 & 11 & 4 & 14 & 8 & 9 \\
\hline Total & 101 & 100 & 100 & 100 & 100 & 99 & 101 & 100 \\
\hline
\end{tabular}

Note: Percentages may not sum to 100 because of rounding. 
pated negative relationship for those under age 30 . The mean monthly wage for primary, middle, and high school-educated males under age 30 is 42.3, 41.4 , and 34.8 renminbi (RMB) respectively; for females the means are 41.3, 40.2 , and 35 . (One RMB was equivalent to US\$0.65 at the time this study was conducted.)

The mean monthly income per household in Red Sky in December 1981 was $131.5 \mathrm{RMB}$, or slightly higher if pension income is included. This figure refers to basic wages only and does not include bonuses, which have been increasing in value since 1979. If each wage is adjusted by adding 7.5 RMB, the average monthly bonus at the time of the study, the mean wage for males was 63.8 RMB; for females it was substantially less-52.3 RMB. (These figures are derived from households including at least one married woman.) People working in neighborhood enterprises earned less and, in 1981, could not generally count on monthly bonuses. If they are excluded, the average wage was $64 \mathrm{RMB}$ for males and 53.1 for females

The income of Red Sky workers is similar to that of urban workers elsewhere. The State Statistical Bureau estimates the mean monthly household income per person in urban China in 1981 to be 38 RMB (People's Daily, 7 March 1983). A 1980 survey of 500 worker families in Tianjin indicated an average monthly per capita wage of $39.4 \mathrm{RMB}$, after deducting what was spent for the support of elderly people living elsewhere. The figure includes bonuses and a monthly subsidy of 5 RMB paid since October 1979, as compensation for a rise in the price of some foodstuffs (Li Hongfa 1981:45). If a 7.5 RMB bonus correction is added to the mean per household person wage in Red Sky (1981), the result, $41 \mathrm{RMB}$ (or $43 \mathrm{RMB}$ if pension income is included), is very similar to those for Tianjin and urban China generally. ${ }^{3}$

For many years since 1949, Chinese policy has stressed egalitarianism. Until recently the slogan was "everyone eating out of the same big pot." Full employment and the leveling of income differences have long been major objectives in the People's Republic of China. The promise of full employment has already been closely approached in Red Sky. To what extent have income differences also been narrowed?

Whyte and Parish (1984) report considerable equality of income in urban China generally. The figures from Red Sky (Table 4) are in agreement; what difference exists is in the direction of even greater income equality.

The average monthly basic wage earned by workers in Red Sky at the time of the study ranged from 33 RMB for neighborhood enterprises to 90

3. My colleague in Tianjin, Pan Yunkeng, using essentially the same data set as that used here, has also calculated the monthly per family member income including wages, bonuses, and welfare payments. The result is only 2.5 RMB higher than the figure provided here. Of all urban localities surveyed as part of the Five Cities Project, Tianjin has the lowest per capita income. The highest reported-51 RMB-was for Shanghai (Five Cities Family Research Project Group 1985:419). 
Table 4. Income inequality: Red Sky, urban China, and developing societies

\begin{tabular}{lccc}
\hline Location & $\begin{array}{c}\text { Gini } \\
\text { coefficient }\end{array}$ & $\begin{array}{c}\text { \% of income earned } \\
\text { by richest } 10 \% \\
\text { of households }\end{array}$ & $\begin{array}{c}\text { \% of income earned } \\
\text { by poorest } 40 \% \\
\text { of households }\end{array}$ \\
\hline Red Sky & .23 & 19 & 25 \\
$\begin{array}{l}\text { Urban China } \\
\begin{array}{l}\text { Developing market } \\
\text { societies (average) }\end{array}\end{array}$ & .25 & 21 & 25 \\
\hline
\end{tabular}

Source for urban China and developing market societies: Whyte and Parish (1984).

RMB for cadres (Table 5). The fact that the better-paid occupations are largely dominated by men undoubtedly contributes to their higher average salary. The most poorly paid jobs, those in neighborhood enterprises, are almost exclusively given to older women. Among younger workers the wage gap is narrow. While it is possible that, with increasing age, men will advance more quickly than women and once again produce a gender gap, during their most fertile years women do make a substantial contribution to domestic income. Although they earn less than men, they provide 41.9 percent of domestic income.

\section{MARRIAGE CUSTOM AND PRACTICE}

The data from Red Sky show substantial progress in removing obstacles to education for women. Progress has also been made in providing women with access to nondomestic employment and in narrowing the gender difference in wages. Increasing involvement of young people in the industrial work force and growing reliance on wage income have contributed to individual independence. This in turn has made it possible for the urban young to respond positively to attempts to shift responsibility for the selection of spouses from parents to children. Informants claim that marriage is now contracted to fulfill the needs and aspirations of the individual rather than those of parents and family. This change has affected nearly all aspects of marriage custom and practice.

\section{Universality of and age at marriage}

In Red Sky marriage is virtually universal, at least for those of ages 40 and over (Table 6). However, the proportions of unmarried men and women under age 35 are unusually high, even by Chinese standards.

People marry late in Red Sky. Between the early 1930s and the late 1970s the mean age at marriage increased continuously for both sexes and the 
Table 5. Monthly wages, by type of employment and sex: Red Sky, December 1981

\begin{tabular}{|c|c|c|c|c|c|c|}
\hline \multirow[b]{3}{*}{ Employment } & \multirow[b]{3}{*}{$\begin{array}{c}\text { Mean basic wage } \\
\text { (RMB) }\end{array}$} & \multicolumn{5}{|c|}{ Wage with bonus adjustment } \\
\hline & & \multicolumn{2}{|c|}{ Males } & \multicolumn{2}{|c|}{ Females } & \multirow{2}{*}{$\frac{\text { Both sexes }}{\begin{array}{c}\text { Mean } \\
\text { (RMB) }\end{array}}$} \\
\hline & & No. & $\begin{array}{l}\text { Mean } \\
\text { (RMB) }\end{array}$ & No. & $\begin{array}{l}\text { Mean as } \\
\% \text { of male }\end{array}$ & \\
\hline Local (neighborhood) enterprise & 33 & 3 & 33 & 30 & 124 & 40 \\
\hline Service & 45 & 98 & 55 & 66 & 87 & 52 \\
\hline Industrial & 46 & 249 & 56 & 253 & 91 & 53 \\
\hline Office & 56 & 103 & 69 & 89 & 84 & 64 \\
\hline Cadre & 90 & 57 & 98 & 2 & 93 & 97 \\
\hline Technical or professional & 62 & 49 & 76 & 41 & 83 & 70 \\
\hline All types & 51 & 559 & 64 & 481 & 81 & 59 \\
\hline
\end{tabular}


Table 6. Population ever married, by age and sex: Red Sky, 1981; China, 1982 (percentage)

\begin{tabular}{|c|c|c|c|c|c|c|}
\hline \multirow[b]{3}{*}{ Age } & \multicolumn{4}{|c|}{ Red Sky } & \multicolumn{2}{|c|}{ All China } \\
\hline & \multicolumn{2}{|c|}{ Males } & \multicolumn{2}{|c|}{ Females } & \multirow{2}{*}{$\frac{\text { Males }}{\%}$} & \multirow{2}{*}{$\frac{\text { Females }}{\%}$} \\
\hline & No. & $\%$ & No. & $\%$ & & \\
\hline $15-19$ & $89^{\circ}$ & - & 60 & - & 1 & 4 \\
\hline 20 & 15 & - & 10 & - & 7 & 25 \\
\hline 21 & 25 & - & 14 & 7 & 13 & 37 \\
\hline 22 & 17 & - & 15 & - & 24 & 51 \\
\hline 23 & 24 & - & 25 & 12 & 36 & 67 \\
\hline 24 & 26 & 8 & 26 & 15 & 49 & 79 \\
\hline 25 & 23 & 17 & 21 & 10 & 62 & 88 \\
\hline 26 & 22 & 36 & 13 & 46 & 71 & 93 \\
\hline 27 & 11 & 64 & 17 & 65 & 79 & 96 \\
\hline 28 & 17 & 88 & 22 & 95 & 84 & 98 \\
\hline 29 & 15 & 80 & 16 & 75 & 87 & 99 \\
\hline $30-34$ & 51 & 88 & 56 & 88 & 91 & 99 \\
\hline $35-39$ & 43 & 98 & 56 & 96 & 93 & 100 \\
\hline $40-44$ & 54 & 100 & 61 & 100 & 94 & 100 \\
\hline $45-49$ & 70 & 100 & 79 & 100 & 96 & 100 \\
\hline 50-59 & 113 & 100 & 107 & 100 & 97 & 100 \\
\hline $60-79$ & 59 & 100 & 65 & 100 & 97 & 100 \\
\hline$\geq 80$ & 1 & 100 & 7 & 100 & 98 & 100 \\
\hline
\end{tabular}

Source for all China: Banister (1984:249).

age difference between spouses gradually narrowed (Figure 3). Although the data set is small, there are indications of unusual rises in marriage age during the mid-1930s and again during the early and mid-1940s, both exceptionally difficult periods. During the mid-1930s Japanese troops occupied Tianjin and the surrounding countryside; there was also a major flood in 1939. The early and mid-1940s were years of warfare and famine, and many men were taken off to forced labor. The end of the war was associated with a drop in the age at marriage for males as many returned from military service or from forced labor. At the same time, general improvement in the economic sitiuation made it possible for many to consider earlier marriage. This undoubtedly contributed to the narrowing spousal age difference during the period.

Pre-1949 civil law established minimum marriage ages of 18 for men and 16 for women, thresholds that were raised by the Marriage Law of 1950 to 20 for men and 18 for women. In 1981 a revised Marriage Law raised 


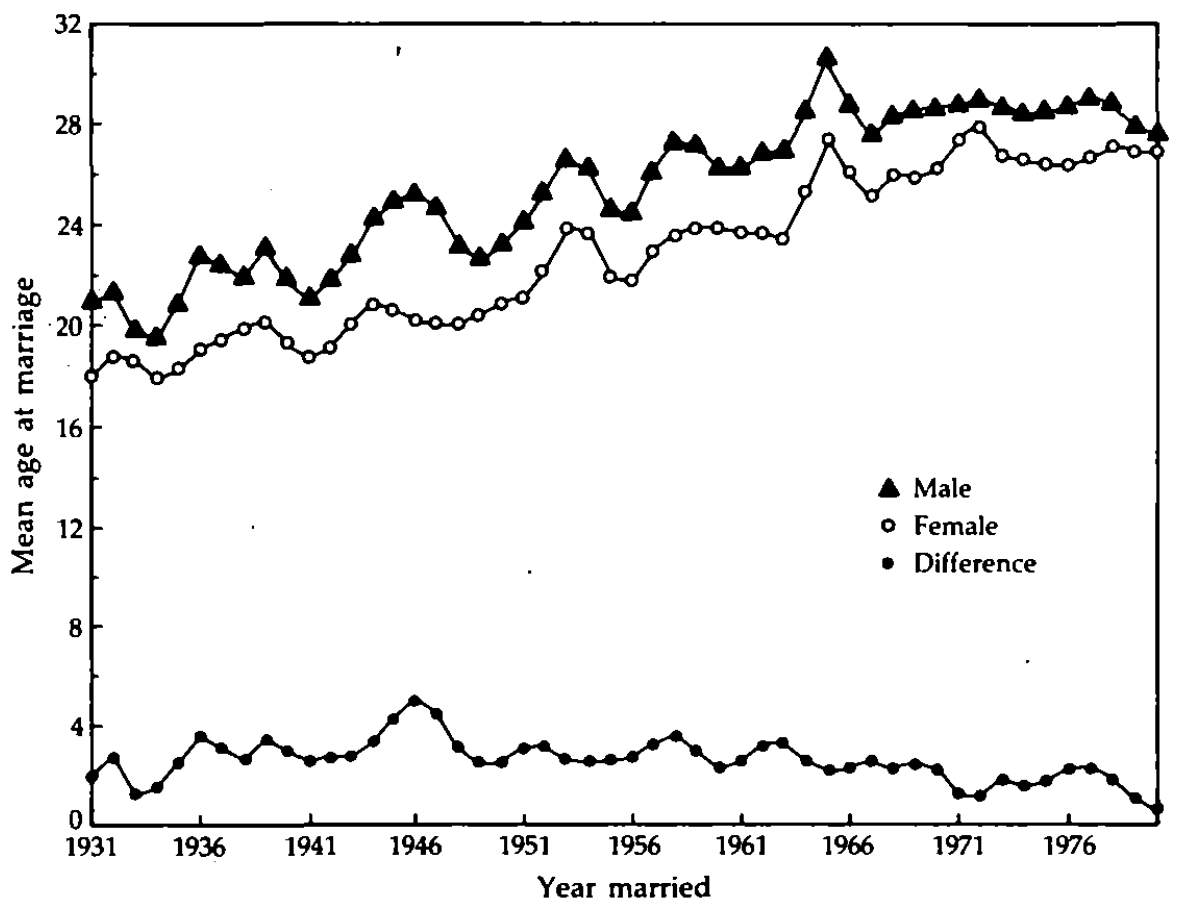

Figure 3. Mean age at marriage, by year married: Red Sky, 1931-80 (three-year moving average)

Note: Female ages are based on all Red Sky women and on women in the adjoining neighborhood for whom data were available.

the minimum ages once again to 22 for men and 20 for women. Before 1949, though, the legal requirements were not effectively enforced. After 1949, in addition to legal enforcement, administrative obstacles were used to press young people to delay marriage beyond the minimum ages. As a result, the mean age at marriage rose sharply. For reasons that are not clear, the marriage age seems to have dropped during the mid-1950s, especially during the 1955 "high tide" push to higher-order agricultural producers' cooperatives. People continued to marry above the legal age even then, but the administrative restraints that had held marriage age above legal requirements may have been relaxed somewhat. Restraints were evidently reimposed after 1956, however, and were maintained until the dislocations associated with the Great Leap Forward (1958) and the "three bad years" (1959-61).

In 1962 a concerted and systematic family planning program was initiated that renewed the emphasis on late marriage. Another rise in age 
at marriage therefore occurred from 1962 until the Cultural Revolution, when administrative restraints on marriage were once again relaxed for a few years. From about 1972, when family planning was reinstated, administrative policy required that both spouses be above 25 at marriage or that their combined age be at least 50 (Five Cities Family Research Project Group 1985:63; see also Coale 1984:41-42). Since 1979, however, with increasing emphasis on single-child families, administrative requirements have been lowered to about 23 for women, reportedly to alleviate concern about difficult births.

Data from the Five Cities Project indicate much the same trend in age at marriage. Since 1977 about 72 percent of urban women have married between the ages of 25 and 29, and another 12 percent have married later. Fifty-nine percent of urban men married between the ages of 25 and 29, with another 37 percent marrying even later (Five Cities Family Research Project Group 1985:264-94). In Red Sky the mean age at marriage (1977-81) was 28 for men and 26.9 for women.

In all Chinese cities surveyed, then, the actual ages at which young people marry are still substantially higher than either the law or administrative restraints would require. Chinese researchers have suggested several reasons for the continued delay (Five Cities Family Research Project Group 1985:23, 35, 63, 103, 144, 177, 197-98; see also Lyle 1980:261-62). People may delay marriage to provide more time for education and career development. Moreover, because the educational attainment and income of women have improved, women are in a position to exert more control over when they will marry than was true in the past. As young people assume more responsibility for providing the resources necessary for marriage and the establishment of a household and as they depend less on others economically, they may even find it necessary to delay marriage. Many recently married people who were sent to the countryside during the Cultural Revolution returned to the city only in their late 20 s. They might well require added time to prepare for marriage. Although some couples register marriage early to establish a claim for scarce housing, most probably assess the housing situation and wait until they believe that space is likely to be made available. In the allocation of housing, moreover, priority is reportedly given to age at marriage more than to time married.

The data from Red Sky do not, however, support a positive relationship between educational attainment and age at marriage. When I broke the data down by period married (1948 or earlier, 1949-57, 1958-65, 1966-75, and 1976 or later), sex, and level of education, the results were inconsistent and the differences statistically insignificant, although it is possible that the small size of my universe obscured subtle differences. There is some suggestion of a positive relationship between education and age at marriage in data from the Five Cities Project, but because that analysis does 
not control for year or period married it is not definitive (Five Cities Family Research Project Group 1985:275-83, 295-303).

It is well known that rural people marry earlier than urban people in China (Coale 1984:41-42). It is possible then that increasing age at marriage in Red Sky was in some part a result of the decreasing proportion of residents with rural backgrounds. When I analyzed the data by period married, sex, and origin (rural or urban) of natal family at marriage, however, the results were again inconsistent and the differences in marriage age insignificant except for females married between 1949 and 1957. During that period women from urban families did marry significantly later than those from rural families (23.2 compared with 21.1; $\mathrm{p}=.009)$. That difference may be important because the substantial in-migration of rural women to Tianjin during that time could have moderated the general rise in marriage age. The larger proportion of rural women during the early post-Liberation years cannot be the whole story, however, because age at marriage had been rising steadily for both rural and urban women (and men). Since the difference between rural and urban men was not great in any period, it is unlikely that differences in provenance contributed substantially to the rise in male age at marriage.

It is likely that legal and administrative controls contributed more to the overall rise in marriage age since 1949 than did level of education, ruralurban provenance, or some increase in the economic preparation necessary to marriage. Why people have continued to delay marriage despite the general relaxation of such restrictions since 1979 is not clear, though. Regardless of education and origin, men and women continue to marry later than they are required to by law or administrative policy. The answer to this question will require more study, using larger data sets that allow finer controls.

\section{Selecting a spouse}

I questioned 531 women in Red Sky and the adjacent neighborhood about how they met their (first) spouses, how long they knew their husbands before marriage, and how they would judge the economic status of their families relative to that of their husbands'. Most of the women had been formally introduced to their husbands before marriage, by parents, other relatives, neighbors, or other go-betweens. Although most couples continue to rely heavily on formal introductions of some sort, the proportion of couples who met on their own and married without any formal introduction has been increasing since 1949, with peaks during periods of social and economic disruption (Figure 4). Data from the Five Cities Project indicate similar trends (Five Cities Family Research Project Group 1985:307-15). As women were drawn into the labor force, fellow workers played an increas- 


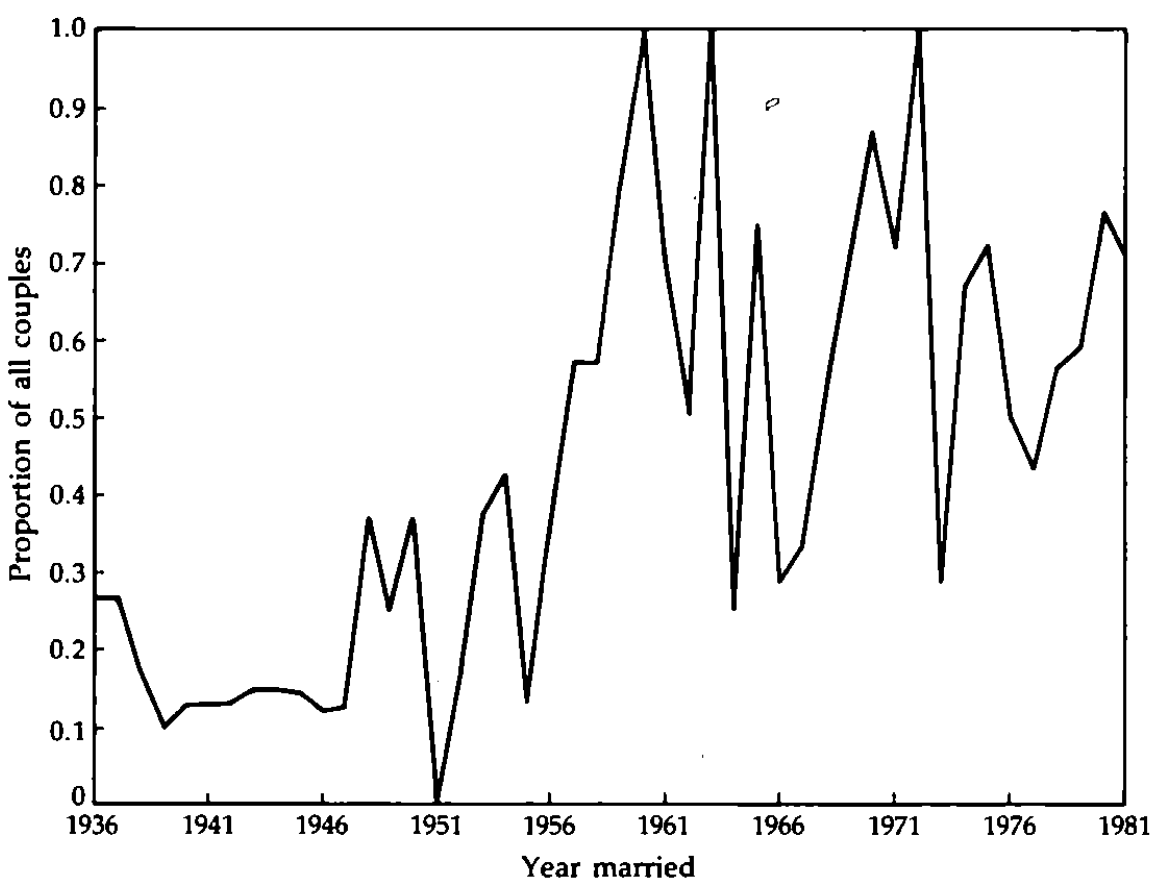

Figure 4. Proportion of couples who met on their own or without formal introduction, by year married: Red Sky, 1936-81 (five-year moving average)

ing role, from 10 percent of introductions before 1949 to 62 percent during the Great Leap Forward (1958), when women were particularly called upon to work outside the home. The proportion of marriages based on introductions by fellow workers has continued to be about 45 percent since 1965 . If marriages involving either no formal introduction or an introduction provided only by fellow workers can be considered "new" in the Chinese context, then the proportion of new-mode marriages has increased dramatically since 1949 .

While premarital relations between the sexes have not become casual or relaxed, the traditional separation of the sexes has been substantially modified since 1949. Young people now have more opportunity to meet, and when they marry they have generally known each other longer than in the past. The median number of months acquainted has risen consistently from less than one for couples married before 1949 to more than twenty-eight for those married since 1976. Nearly 50 percent of women married between 1958 and 1965 reported having known their husbands for one to two years before marriage; 29 percent knew their husbands for more than 
Table 7. Time (in months) acquainted at marriage, by year married: Red Sky, December 1981 (percentage)

\begin{tabular}{|c|c|c|c|c|c|}
\hline \multirow[b]{2}{*}{ Months } & \multicolumn{5}{|c|}{ Year married } \\
\hline & $<1949$ & $1949-57$ & 1958-65 & $1966-75$ & $>1975$ \\
\hline 0 & 71 & 25 & 4 & - & - \\
\hline $1-12$ & 19 & 26 & 18 & 25 & 20 \\
\hline $13-24$ & 5 & 22 & 49 & 30 & 26 \\
\hline$>24$ & 6 & 27 & 29 & 45 & 55 \\
\hline \multicolumn{6}{|l|}{ Total } \\
\hline$\%$ & 101 & 100 & 100 & 100 & 101 \\
\hline No. & 238 & 104 & 51 & 80 & 82 \\
\hline Median in months & 0.2 & 12.3 & 23.0 & 23.8 & 28.5 \\
\hline
\end{tabular}

Note: Percentages may not sum to 100 because of rounding.

two years. After 1976 the proportion acquainted for more than two years increased even more (Table 7).

Increasing premarital familiarity constitutes a major break with the past. It indicates an increasing stress on the conjugal relationship relative to the parent-child bond. There is reason to believe that this change is not unique to Red Sky; figures provided by Martin Whyte (private communication) indicate much the same trend-the percentage of couples acquainted for fewer than six months in his general urban sample dropped from 11, to 3 , to 5 percent for women married during 1958-65, 1966-70, and 1971-77, respectively. The proportion of couples acquainted for two or more years rose from 32 to 53 percent and then dropped to 45 percent during the same periods. These data have been classified a bit differently from mine, but the results are not dramatically different.

Although I cannot precisely assess the relative status of families that become linked through marriage, it is possible to form a crude impression. In Red Sky, of the women willing to estimate the economic status of their families relative to that of their (first) husbands, the majority judged them to have been about the same. In 61 percent of the cases where family statuses were judged to be different, the husband's family was better off-a pattern consistent with the traditional Chinese view that marriage should link families "with equal gates" or, if unequal, then the husband's family should have the advantage. Data from the Five Cities Project confirm a strong preference for equal economic and educational status. Couples tend to have similar educational and occupational backgrounds, and, even more 
commonly, their parents have similar occupations. Where differences are found, the husband and his family usually have the advantage (Five Cities Family Research Project Group 1985:109, 178, 221-22).

When the data are examined by period married it is evident that "equality of gates" has generally been the rule in Red Sky, with more than 75 percent of marriages in all periods linking families of similar status. Still, the data do suggest some subtle changes. Immediately after Liberation, the proportion of marriages involving families with "equal gates" rose to levels well above those just prior to 1949, perhaps reflecting concern about family class labels as well as the economic leveling of families that resulted from reforms during that period. The Great Leap Forward was apparently associated with a drop in affinal equivalence, possibly because extreme economic dislocation created new disparities. The egalitarianism of the early years of the Cultural Revolution was associated with another rise in affinal balance, and, during the most recent years, yet another rise is apparent, perhaps the result of general and widespread improvement in income.

The statistical significance of changes in the nature of marriages of unequal status cannot be evaluated because the number of such marriages has been very small in all periods. The data nevertheless suggest a gradual and consistent shift away from hypergamy-from situations in which females marry "up." Year-by-year analysis suggests four periods during which the proportion of marriages in which women married "down" exceeded the proportion of hypergamous marriages: (1) in 1940, during a period of political and economic dislocation and one year after the Tianjin flood; (2) in 1956, during the "State-Private Joint Management Movement"; (3) during 1958-60, the worst years of the Great Leap Forward; and (4) possibly again during 1966-74, which corresponds to the Cultural Revolution.

Once again, the data base is simply too small for us to be sure that these apparent shifts were statistically significant. But if they were, then the timing suggests that unusual incidences of marriage down have been associated with profound economic stress and sometimes also with periods of radicalism during which family class labels assumed special importance. The special emphasis placed on class status during the radical shift of the Cultural Revolution had an impact on marriage, for example. That less than 50 percent of the asymmetrical marriages were hypergamous during this period confirms what many claim-namely, that some families found it expedient to seek political security by marrying daughters into families of more humble but more politically acceptable status. It is also possible that daughters were more often kept at home while sons were sent to the countryside and that this gave them both a steady job and more seniority at the time of marriage. 
Table 8. Type of engagement ceremony, by year of marriage: Red Sky, pre-1949 to post-1975 (percentage)

\begin{tabular}{|c|c|c|c|c|c|}
\hline \multirow[b]{2}{*}{ Type of ceremony } & \multicolumn{5}{|c|}{ Year married } \\
\hline & $\begin{array}{l}<1949 \\
(\mathrm{~N}=217)\end{array}$ & $\begin{array}{l}1949-57 \\
(\mathrm{~N}=118)\end{array}$ & $\begin{array}{l}1958-65 \\
(\mathrm{~N}=60)\end{array}$ & $\begin{array}{l}1966-75 \\
(\mathrm{~N}=92)\end{array}$ & $\begin{array}{l}>1975 \\
(\mathrm{~N}=84)\end{array}$ \\
\hline $\begin{array}{l}\text { Ceremony with formal } \\
\text { exchange of gifts }\end{array}$ & 52 & 13 & 3 & 2 & 8 \\
\hline $\begin{array}{l}\text { Simple ceremony with } \\
\text { few or no gifts }\end{array}$ & 9 & 17 & 15 & 9 & 21 \\
\hline No ceremony or gifts & 39 & 70 & 82 & 88 & 69 \\
\hline All types & 100 & 100 & 100 & 99 & 98 \\
\hline
\end{tabular}

Note: Percentages may not sum to 100 because of rounding.

\section{Marriage rituals}

My information on marital procedures and customs, although based entirely on questionnaires and interviews, nonetheless shows significant changes since 1949.

Before Liberation, marriage was usually preceded by a formal engagement and gift exchange between families. After 1949 Chinese policy discouraged engagement rituals, especially insofar as they involved exchanges of gifts; the figures indicate that Red Sky residents have been responsiveduring the years after Liberation engagements were generally very simple (Table 8). With liberalization and increasing economic prosperity since 1976, however, interest in marital ceremony and ritual has renewed. Nevertheless, few marriages are now preceded by the sort of elaborate gift exchanges once much frowned upon by Chinese authorities.

Policy after 1949 also discouraged the giving of bridewealth and dowries-practices that, like the giving of engagement gifts, were considered "feudal" rituals that subjugated women to men and young couples to their parents upon whom they had to depend both for the selection of spouses and for the arrangement and conduct of marriages. The incidence and nature of these transactions has therefore changed substantially since 1949. In the past, both bridewealth and dowries were accumulated by families to be used in an exchange between families. More recently, however, potential spouses have assumed an increasing role in the preparation of these gifts, and items prepared are used exclusively to equip the new household. Red Sky residents indicated that, especially since 1976, bridewealth has been more and more delivered to the prospective bride rather than to 
Table 9. Type of bridewealth, by year of marriage: Red Sky, December 1981 (percentage)

\begin{tabular}{lccccc}
\hline & \multicolumn{5}{c}{ Year married } \\
\cline { 2 - 6 } Type of bridewealth & $<1949$ & $1949-57$ & $1958-65$ & $1966-75$ & $>1975$ \\
\hline $\begin{array}{l}\text { None } \\
\begin{array}{l}\text { Small: formerly a few } \\
\text { items of clothing; now } \\
\text { under 500 RMB }\end{array}\end{array}$ & 46 & 64 & 60 & 61 & 23 \\
$\begin{array}{l}\text { Medium: formerly a few } \\
\text { items of jewelry; now }\end{array}$ & 29 & 17 & 18 & 16 & 3 \\
$\begin{array}{l}\text { 500-1,000 RMB, a bicycle, } \\
\text { and a few items of furniture }\end{array}$ & 19 & 14 & 17 & 20 & 36 \\
$\begin{array}{l}\text { Large: formerly considerable } \\
\text { jewelry; now 1,000 RMB or } \\
\text { more, a watch, bicycle, } \\
\text { TV, and complete set of }\end{array}$ & & & & & \\
furniture & & & & & \\
$\begin{array}{l}\text { Total } \\
\%\end{array}$ & 6 & 4 & 5 & 4 & 38 \\
$\quad$ No. & 100 & 99 & 100 & 101 & 100 \\
\hline
\end{tabular}

Note: Percentages may not sum to 100 because of rounding.

her family. In no sense is it thought of as an instrument of purchase intended, in some part at least, to enrich the coffers of larger family units.

Before 1949, bridewealth was provided in more than half of all marriages (Table 9). Because families were generally poor and conditions of life difficult, however, the bridewealth was meager in value. After Liberation, just as the importance of engagement ceremonies and exchanges declined, so too did the giving of elaborate and costly bridewealth. And, as liberalization was accompanied by renewed interest in engagement ceremonies and gift exchange, so too did the incidence and amount of bridewealth increase. Interest in bridewealth was renewed as economic conditions in general, and family incomes in particular, improved and as government concern was relaxed. Thus, 77 percent of all marriages since 1976 reportedly involved bridewealth-a proportion even higher than that in the years just before Liberation.

In addition to the giving of bridewealth, most pre-1949 marriages involved dowries, usually very simple ones. The pattern for dowries after 1949 closely paralleled that for bridewealth (Table 10). Between 1949 and 1975 most marriages were without dowries. As in the case of engagement 
Table 10. Type of dowry, by year of marriage: Red Sky, December 1981 (percentage)

\begin{tabular}{|c|c|c|c|c|c|}
\hline \multirow[b]{2}{*}{ Type of dowry } & \multicolumn{5}{|c|}{ Year married } \\
\hline & $<1949$ & $1949-57$ & $1958-65$ & $1966-75$ & $>1975$ \\
\hline None & 40 & 63 & 60 & 60 & 18 \\
\hline $\begin{array}{l}\text { Simple: formerly and now } \\
\text { a few items of clothing }\end{array}$ & 30 & 17 & 21 & 8 & 7 \\
\hline $\begin{array}{l}\text { Medium: formerly a few } \\
\text { items of clothing and } \\
\text { furniture, some household } \\
\text { necessities; now same but } \\
\text { no furniture }\end{array}$ & 20 & 14 & 16 & 25 & 43 \\
\hline $\begin{array}{l}\text { Large: formerly considerable } \\
\text { clothing, bedding, complete } \\
\text { set of furniture, and house- } \\
\text { hold necessities; now same } \\
\text { but no furniture }\end{array}$ & 10 & 5 & 3 & 6 & 32 \\
\hline $\begin{array}{c}\text { Total } \\
\%\end{array}$ & 100 & 99 & 100 & 99 & 100 \\
\hline No. & 231 & 104 & 57 & 83 & 72 \\
\hline
\end{tabular}

Note: Percentages may not sum to 100 because of rounding.

and bridewealth, the incidence and magnitude of dowries increased after 1975.

Traditional Chinese marriages also involved elaborate ceremony and costly feasting, mainly in the home of the groom but often also in that of the bride. Likewise, in Red Sky most marriages before 1949 (76 percent) were celebrated with ceremonies that included the worship of gods and ancestors as well as substantial feasts. Although most marriages continue to be celebrated ceremoniously, the ceremonies have generally become simpler. Elaborate feasting, and especially worship of gods and ancestors, became much less common in Red Sky, at least until the liberalization begun after 1975. Two simple, more frugal types of ceremonies-collective and "traveling" weddings-were officially recommended after 1949 . Collective weddings are organized periodically by large work units or by the Women's Federation. The cost of such a wedding is negligible because several couples are married at the same time. Traveling weddings involve a minimum of ceremony and feasting. In principle, having officially registered their marriage, a husband and wife simply leave on their honeymoon. In some cases their work units provide a subsidy for the trip. Weddings marked in this way, however, without any ceremony at all, have attracted little at- 
tention and have been very rare indeed. In fact, since 1976, the more spartan weddings of earlier years have virtually disappeared. Nearly all weddings now involve ceremony and in most cases rather elaborate feasts. These general trends as described for Red Sky have likely been characteristic of other Chinese cities as well (Five Cities Family Research Project Group 1985:78, 150-51, 178, 204-5).

Marriage feasts in the groom's home were modest even before Liberation, their simplicity undoubtedly necessitated by the economic and political dislocations under which families labored. Sixty-seven percent of all grooms' feasts served fewer than 50 people. Such feasts continued to be modest until recently. Since 1976, however, many more families have provided wedding feasts, and the number of guests has increased substantially. Over half of all weddings since 1976 feasted fifty or more guests in the groom's home, and in many cases (17 percent) the number of guests exceeded one hundred. Wedding feasts in the bride's home have always been simpler and less common. That they continue to be less important than those in the groom's home is indicated by the fact that, even since 1976, they have been kept simple.

In sum, increasing interest in wedding ceremonies and feasts, like the growing interest in dowries and bridewealth, reflects not only an increasing economic capacity for such expenditure and a more abundant supply of necessary goods, but also a release of traditional notions about how status is to be expressed. The idea that providing large dowries and bridewealth and having lavish wedding feasts confers status has clearly not died in urban China. Nevertheless, the changes in marriage rituals and procedures that have occurred since 1949 have clearly encouraged the expression of free marital choice, giving young people greater voice in the selection of their spouses than in the past and ensuring that marriage is more often predicated on some degree of familiarity. These changes might be expected to produce a stronger, more independent conjugal relationship, which in turn could affect childbearing strategies.

\section{Postmarital residence}

Traditional Chinese preference for patrilocality notwithstanding, the frequency of neolocal marriages had been increasing in Red Sky even before 1949 (Figure 5). A pattern of migration in which poor rural men came to live in the city and were later joined by wives and children probably contributed substantially to that rise. Although neolocality has been the most common form of postmarital residence for some time, there were short periods during which the incidence of patrilocality appears to have increased somewhat. This happened during the worst years of the Japanese occupation, for example, and again during the "three bad years" (1959-61). 


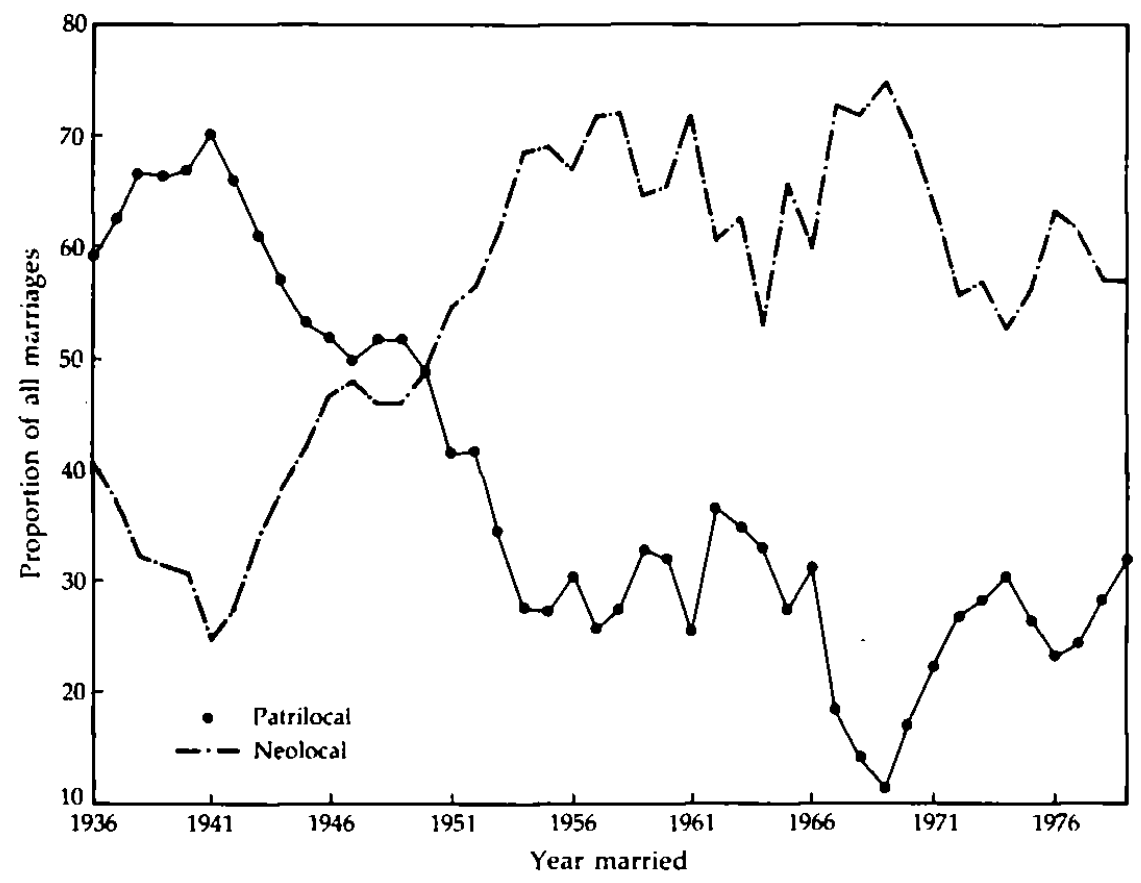

Figure 5. Postmarital residence, by year married: Red Sky, 1936-79 (five-year moving average)

In recent years, and especially since 1969 , increasingly scarce housing has put a minor restraint on neolocality and on residential mobility in general. Although a great deal of housing was constructed in West Mountain Street during the early 1950 s as the area was converted into a new industrial zone, additional investment in housing stock was thereafter considered a frivolous use of resources. As a result, the mean sleeping space per person in Red Sky was only 5.06 square meters in 1981. When Tianjin's housing stock was suddenly and seriously depleted by two major earthquakes in 1976, many people constructed small living huts in the streets. This may account for the sudden increase in neolocality for that year. Temporary housing constructed after the earthquake was gradually eliminated, but new housing has remained scarce. It is no surprise, then, that the proportion of patrilocal marriages increased slightly after 1976 (Figure 5). The official policy on housing construction has changed dramatically since 1976, however, and the problem of scarce living space is now being met head on. It is likely that the new construction will ease the problem in the course of time and that the potentiality for neolocality will increase. 
The general increase in neolocality that occurred in Tianjin has also been characteristic of other cities. Data from the Five Cities Project show that neolocality has risen to more than 50 percent of all marriages while patrilocality has declined. 4 Those data also reveal a minor resurgence of patrilocality after 1976 (Five Cities Family Research Project Group 1985:318). The data from particular cities, however, reveal differences that reflect problems specific to each city or neighborhood. Chinese researchers, who are inclined to attribute the general rise in neolocality to the "modernization" process, propose that differences in housing availability constitute the major reason for variation from city to city. The recent minor resurgence of patrilocality, in their view, is a result of heightened scarcity of housing (Five Cities Family Research Project Group 1985:45, 154, 173, 205).

Implied in this interpretation is the idea that, in the normal course of modernization and urbanization, married couples would live alone if they could (see, for example, Five Cities Family Research Project Group 1985:173). In the field, however, it was not unusual to hear people say that they would live with parents if they could, and living with parents clearly has advantages. That most young women work outside the home and are also better educated than their mothers-in-law gives them considerable voice in family affairs. Their status relative to that of the older women with whom they live is therefore higher than in the past. At the same time, the older women in the household can help with shopping, housecleaning, cooking, and childcare, which is especially important given the continued shortage and the cost of daycare facilities. Because apartments are so crowded, however, newly married couples usually have to move out when new space becomes available. In such circumstances, movement may be less a reflection of desire than a response to crowded housing.

Although young women may not move away because of some uniform desire to escape the husband's mother, there is some reason to believe that older women may, for their part, find less advantage to remaining with their daughters-in-law now than in the past. Data from a 1985 survey of 1,000 households indicate a decline in the percentage of elderly people expressing a desire to live with their children. The percentage reportedly fell 10.1

4. Comparison of my tables with those in the published report of the Five Cities Project reveals some minor differences. In part this is because, in the course of our separate data analyses, my Chinese colleague Pan Yunkeng and I used slightly different classifications. Another reason is that the Chinese researchers involved in the Five Cities Project did not include in their analyses single persons living in factory dormitories. Yet another source of difference, according to my Chinese colleague, is that my original data set was "slightly updated" shortly after my departure from Tianjin. If that is true, then the higher incidence of neolocality after 1977 could reflect the fact that many new buildings were completed in 1981 and 1982, making apartments available to young couples who had earlier been living with parents. 
percent-to only 50 percent-between 1983 and 1985 (China Daily News, 2 January 1986:4). Nevertheless, few elderly people actually live alone in Red Sky. Only 4 percent of all people of ages 60 and over (six females and nine males) were living alone in 1981 . Most older residents were members of nuclear (49 percent) or extended (45 percent) household units. Thus, even though many more young people leave their parents at marriage than in the past, most of the elderly continue to enjoy the security provided by living with spouses or children (see Davis-Friedmann 1985:155-56).

It may be significant, in this connection, that when I compared the Red Sky residence figures with data on housing per person from the Five Cities Project I discovered that, among eight urban localities surveyed, those with the highest rates of neolocality were also those with the least apartment space per person (Five Cities Family Research Project Group 1985:437). Tianjin and Tuanjie Hu in Beijing have the least space per person and the highest rates of neolocality. Both are "new" neighborhoods, having been constructed during the early 1950s. In these neighborhoods traditional " $U$ "shaped compounds have been replaced by tenements with smaller, oneor two-bedroom apartments, suitable only for a married couple with unmarried children. The recent rise in patrilocality that has taken place in these two localities may simply reflect the fact that housing is scarce in a broader sense-apartments are not only crowded, but alternative possibilities have diminished. Without additional evidence, then, we cannot directly infer values and attitudes about living with parents from the rate of neolocality characteristic of a particular locality.

While neolocal and patrilocal marriages have been most common in Tianjin, other options do exist. There have always been situations in which husbands joined the families of their wives at marriage. Chinese and foreign scholars alike have claimed that such marriages were mainly contracted by poor families who lacked a male heir. Matrilocal marriages have always been rare in Red Sky, though. Only 2 percent of marriages were of this sort before 1949, when families were economically most depressed, and there were none at all between 1949 and 1966. I have detailed information about twenty-two cases of matrilocal marriage in Red Sky and in the adjoining neighborhood. The earliest of these marriages took place in 1916. In not one case since then did any of the children take the wife's surname. In nine out of the twenty-two cases the natal family of the bride had already produced a male heir to carry on the line, and in most cases either the husband's natal family was quite large and had limited living space, or the men were living alone. The mean household size was 3.8 for the women and 5.2 for the men. If the one-person households (those in which the marrying male was alone) are excluded, the mean household size for men marrying matrilocally was 6.2 persons. It would seem, then, that car- 
rying on the patriline of the wife was not the main reason for matrilocal residence in these cases.

Matrilocal residence after marriage is now being encouraged for several reasons. First, the patrilineal bias considered so debilitating finds strength in the residential aggregation of consanguineally related males. Greater flexibility in marital residence would therefore help eliminate this bias. More important, attainment of current family planning objectives, in particular the goal of limiting families to one or at most two children, depends upon providing a guarantee of support in old age. For day-to-day care in old age, people continue to depend heavily on help from children, traditionally from sons. The fact that workers can now anticipate pension income reduces but does not remove this dependence. Many of the older women now reaching retirement age never participated in the nondomestic labor force, or did so only for short periods. They can expect few if any retirement benefits. By attracting an income-earning son-in-law, matrilocality could conceivably mitigate the traditional compulsion for sons, a drive that encourages people to have a second child, especially when the first is female. On the other hand, the same concerns that place a premium on sons inhibit parents from allowing sons to marry matrilocally, which is undoubtedly the main reason for the continued low incidence of these marriages in Red Sky. Although there has been a slight increase since 1966, matrilocal marriages continue to be rare.

"Duolocal" marriage, in which spouses live separately after marriage, has also been rare in Red Sky. Only 16 marriages in Red Sky and its adjacent neighborhood have been of this type, and only during the Cultural Revolution did their proportion reach as high as 5 percent. In some instances young people sent to the countryside during that period found urban spouses to justify requests for permission to return to the city. There also seems to have been some relocation of factories from coastal to inland locations at that time, reportedly in anticipation of war with the Soviet Union and in response to fighting along the border with Vietnam. The movement of workers with their work units may have led to some spousal separation at marriage.

Another marital option that has also had little appeal to Red Sky residents is that in which a girl, adopted in infancy or childhood, is subsequently married to her adoptive brother. In the anthropological literature on China, such marriage is often referred to as "minor" marriage. There is some controversy among scholars over the frequency and functions of this form of marriage, but, like matrilocal marriage, it is commonly believed to have reflected extreme poverty. Analysis of minor marriages in an area of northern Taiwan by Wolf and Huang (1980) indicates no relationship to poverty, however, and while the people of Red Sky have long known depri- 
vation, and while mention of people marrying this way did occur in the course of interviews, none of the people in the study had actually married in this fashion. This finding suggests that even if minor marriages do occur more commonly among the poor, poverty does not necessarily mean that their incidence will increase.

\section{Household form}

In December 1981 there were 494 households in Red Sky, with a mean (and median) household size of 3.7 persons, which appears to be typical for the area (State Statistical Bureau 1983:6-7; State Council Census Office 1983:12-13). Households in Red Sky were predominantly (75 percent) nuclear, consisting only of a married couple and their children, if any. Extended-family households, with two or more conjugal units in different generations, were rare (15 percent), as were single-person households ( 9 percent) and joint-family households, with more than one conjugal unit in the same generation (1 percent). The Five Cities Project likewise indicates a preponderance of nuclear-family households.

Researchers involved in the Five Cities Project also concluded that families have become smaller and that "incomplete-broken" families and those consisting of two or more couples have both substantially declined. They consider these changes to be expected consequences of modernization (Five Cities Family Research Project Group 1985:81-83). Although families probably have become smaller and simpler as well as more complete since 1949 , comparison of natal family form and size at time of marriage with those at present does not provide adequate demonstration of the fact. Since the age at marriage has been increasing for both sexes, it is possible that we are dealing with families at different stages of development. Even if the proportion of incomplete or single-person households has declined, the change cannot be attributed simply to some vague force of "modernization." If the proportion of broken and single-person households was unusually high during the years just prior to Liberation as a result of flood, famine, and war, then the subsequent decline in their proportion may indicate a return to more stable conditions as much as a response to changes associated with the modernization of Tianjin.

\section{Intrafamilial relations: monetary contributions}

Clearly, neolocality and the growing importance of wage labor have altered relationships within the family and the household in Red Sky. Although I was not permitted to visit homes or directly observe family interactions, many informants indicated that women no longer exert the influence and control over their daughters-in-law that they once did. On the other hand, parents no longer lose contact with married daughters who are living away 
from home. Today, daughters often send money and help their parents in nonmonetary ways as well. Of the 419 households for which I have income data, 11 percent reported regularly receiving remittances from relatives. Of those, 71 percent were getting help from daughters and 55 percent were receiving a monthly remittance from sons. The amounts sent by sons and daughters did not differ significantly; the mean remittance sent by sons was $9.1 \mathrm{RMB}$ compared with $9.0 \mathrm{RMB}$ for daughters. Thirty-eight percent of all households reported sending remittances-about 66 percent to the wife's parents, more than those sent to the husband's parents (55 percent). Data from other cities surveyed in connection with the Five Cities Project indicate a range from 28.5 to 54.7 percent sending remittances. The overall proportion of households sending remittances was 35.9 , which is very close to the proportion revealed in my data. The range for households receiving aid was from 2.3 percent to 22.3, with an overall proportion of 11.2, which once again is very close to my figure (Five Cities Family Research Project Group 1985:428, 432).

These findings are striking because, in traditional Chinese contexts, a woman's separation from her family at marriage was virtually complete; it was largely for this reason that girls were said to be "useless," and it was for this reason that female children were frequently disadvantaged in access to education and, in times of shortage, to more basic necessities such as food and medical care. Many elderly women told me that, under present circumstances, daughters may be more helpful and "useful" than sons. While a daughter will come home to clean house for her parents, neither a son nor a daughter-in-law can be relied upon for such tasks. To the extent that daughters continue to support their parents, the pressure for sons may therefore be reduced.

According to data on remittances from the Five Cities Project, the absolute values sent and received in China's cities were small. The overall mean monthly amount was $13.5 \mathrm{RMB}$ to 1.39 recipients; the average remittance received was 21.2 RMB from 2.19 providers (Five Cities Family Research Project Group 1985:429, 430, 432). These values per provider are close to those for Red Sky. One of the project's Shanghai surveys indicated that the vast number of remittance recipients were above a poverty line of $25 \mathrm{RMB}$ per person per month, and the researchers concluded from this that remittances were given not primarily for economic reasons but out of filial deference. The data from Red Sky suggest that remittances were not simply an important filial obligation of the young. In fact they constituted a more than nominal contribution to income. Most recipients were elderly (93 percent were over 50); 77 percent belonged to nuclear households, and 7 percent lived alone. The proportion of Red Sky recipients with monthly incomes (wages plus pensions) below the community per family member 
mean (35.8 RMB) was 78 percent. Forty percent of all Red Sky women of ages 55 or over were receiving some kind of remittance from their children. Clearly, a substantial proportion of older people counted on help from their children, and in most cases the amounts contributed were more than symbolic.

Because women now commonly live alone with their husbands, are better educated than in the past, participate fully in the work force, and contribute to the domestic economy with substantial wages and remittances, they have reportedly acquired greater voice over the disposition of their own labor and income. Although they have not attained complete equality with men, even in the domestic sphere, there is little doubt that the husband's mother can no longer exert the influence she did when residence was with the husband's family, when women were raised to illiteracy, and when labor was confined to the home. These changes have contributed to shifting attitudes about the value of daughters, which in turn have likely influenced reproductive strategies.

\section{FERTILITY AND THE DEMOGRAPHIC TRANSITION}

Red Sky has experienced many of the economic and social changes that normally occur with urban-industrial development and that are expected to result in fertility decline-falling mortality, the expansion of access to education, the increasing involvement of women in the nondomestic work force, and the development of independent conjugal families. Of these, access to education and involvement in the work force merit special attention here.

\section{Effect of increased access to education}

Changes in education play a special role in various theoretical approaches linking socioeconomic modernization and fertility decline-in the "demographic transition" model (Notestein 1953; Coale 1975), in the household production model (DeTray 1976; Khan and Sirageldin 1979; Michael 1973; and Schultz 1973), in Easterlin's "synthesis" framework (see Easterlin et al. 1980), and in Caldwell's "wealth flows" theory (see, for example, Caldwell 1982a, 1982b, 1982c; and DeTray 1976). Empirical studies of these approaches have repeatedly confirmed a relationship between education and fertility in developed and developing societies. Several studies indicate that expanded access to formal education may depress fertility. For one thing, access to education often increases the age at which women marry, reducing their lifetime exposure to sexual intercourse (Bongaarts and Menken 1983:34-45; Cochrane 1979:146; and United Nations 1983:68-71). Rising education is also associated with lower infant mortality, which in turn is related to lower fertility (Caldwell 1979; LeVine 1980:S83-85). There is also 
evidence that education alters the perceived costs and benefits of children, as well as the perceived economic advantages of large families, commonly resulting in lower fertility (Arnold et al. 1975; Cochrane 1979:102-9, 112-15; McClelland 1983; Mueller 1972; and Speare 1973). Other studies indicate that education increases knowledge of contraception and fosters more favorable attitudes toward fertility regulation (Cochrane 1979:117-35). Some evidence suggests, however, that education may have a pronatalist effect. For example, increasing the level of education may decrease the rate and duration of breastfeeding and shorten postpartum sexual avoidance, thus reducing postpartum lactational amenorrhea and increasing exposure to sexual intercourse (Bongaarts and Potter 1983:24-25; Caldwell and Caldwell 1977:186-87, 200; Cochrane 1979:92; Nag 1983:164-68, 178-83; and Lesthaeghe et al. 1981:157-68).

My data set is too small to allow the sort of subtle controls that would make it possible to determine precisely how education exerts its effect on fertility in Red Sky (e.g., by controlling for differences in age at marriage, occupation, knowledge and use of contraception, and values with respect to family size and usefulness of children), but it has allowed me to determine whether or not there is any relationship between level of education and fertility (a zero-order correlation). In their analysis of the results of the recent Chinese fertility survey, Caldwell and Srinivasan concluded that "fertility is clearly higher among those least susceptible to government pressure and more likely to find their children productive assets." Using a measure of fertility that incorporates clearly completed fertility with that of younger women who may have ceased reproduction (the parity of women at 35,40 , and 45 years combined), they found that average number of live births varied with level of education and occupation in the expected direction (1984:76). The data for Red Sky also show a relationship between level of education and fertility in the expected direction; the higher the level of education the lower the mean parity achieved (Table 11).5

\section{Effect of female participation in the work force}

Although a relationship between fertility and female participation in the work force has also been asserted and explored in many studies, consensus has yet to be reached concerning the existence, direction, and causes of this relationship. Data from more developed countries generally suggest an inverse relationship between female employment and fertility (Blake

5. Results of the Five Cities Project also suggest a relationship between education and number of births in the expected direction, but the data are not controlled by age of mother. Since better-educated women are also generally younger women and those most subject to family planning pressures, such a control is essential (Five Cities Family Research Project Group 1985:523). 
Table 11. Parity of women of ages 35 and over, by highest educational level attained: Red Sky, December 1981

\begin{tabular}{lrc}
\hline Educational level & No. & Mean parity \\
\hline Illiterate & 206 & 4.1 \\
Literate but no formal schooling & 22 & 3.4 \\
Primary school & 112 & 3.1 \\
Middle school & 81 & 2.8 \\
High school & 54 & 2.8 \\
Vocational school & 5 & 3.0 \\
University or college & 15 & 2.4 \\
\hline
\end{tabular}

1965; Freedman et al. 1963; Mason 1974; Pratt and Whelpton 1956; Ridley 1959; Westoff et al. 1963), but evidence from less developed countries indicates either a positive relationship or none at all (Concepción 1974; Gendell 1967; Goldstein 1972; Jaffe and Azumi 1960; Lee and Cho 1976; Stycos 1965; Stycos and Weller 1967).

According to one view, the higher a woman's potential wage rate, the greater the cost of children relative to alternative goods and thus the fewer children a couple will have (e.g., Becker 1960:209-40; Mason 1974:13; Easterlin 1973). Easterlin asserts, for example, that couples have subjective preferences that specify the combinations of children and alternative "goods." Assuming that children and other "goods" are "scarce," the number of children couples will choose to have will depend not only on preferences or "tastes," but also on the relative costs of children and other "goods" and on total income used to satisfy preferences. In general, rises in income permit an increase in the acquisition of all preferred "goods," including children, as long as there is no change in the relative cost of children. The more expensive children become, however, the fewer children couples will have (Easterlin 1973; Mason 1974; cf., Willis 1973).

Another view is that labor influences fertility through role images"role traditional" women are less likely than "role modern" ones to view work as an alternative to motherhood and are therefore more likely to find satisfaction in having many children (Hoffman and Wyatt 1960; Blake 1965, 1971; Hoffman and Hoffman 1973). Some researchers have also argued that, in addition to a woman's education, the duration of her work experience before marriage, the quality of her jobs before and after marriage, and the timing of her first birth are potential indicators of her preferences and sexrole orientation, both of which in turn influence fertility later in life.

Still others have attributed importance to the role incompatibility that work outside the home creates for women (Collver and Langlois 1962; Jaffe and Azumi 1960; Stycos and Weller 1967; Weller 1968). Where the nuclear 
Table 12. Parity of women of ages 35 and over, by type of employment: Red Sky, December 1981

\begin{tabular}{lrc}
\hline Occupation & No. & Mean parity \\
\hline None & 152 & 4.0 \\
Retired & 99 & 3.7 \\
Local collectives & 62 & 4.1 \\
Service & 28 & 3.3 \\
Industrial & 102 & 3.0 \\
Office & 54 & 2.7 \\
Technical or professional & 37 & 2.5 \\
Cadre & 3 & 2.0 \\
\hline
\end{tabular}

family prevails, as it does in most modem societies, childcare becomes a major problem. High fertility may thus become an obstacle to continued employment and to the benefits to be derived therefrom. The extent of incompatibility will vary with the type of work and the availability of surrogate baby tenders.

The size and nature of my data do not permit a detailed analysis of the factors that account for the relationship between work and fertility in Red Sky, but the data do give a general idea as to the existence of such a relationship. Although many large work units provide nursery facilities for their workers and although neighborhoods sometimes also provide childcare services, the demand for space in nurseries and kindergartens exceeds the supply, and such services are not without cost. Because childcare is still a considerable burden, women with no occupation, those retired, and those employed in neighborhood enterprises would be expected to have the highest mean parity. The data are consistent with this expectation (Table 12). Further, among employed women those in the most "modern" sectors have the lowest parity; industrial workers have lower parity than those in the service sector, and office and technical workers even lower. Although the number of female cadres is small, the fact that their mean parity is lowest is consistent with the expectation that the women most subject to antinatalist pressures would have the lowest parity.

\section{Patterns of fertility change}

Having considered some of the demographic, social, and economic changes that took place as Red Sky modernized, it is useful now to trace the changes in fertility to see if they can be explained by the demographic transition model. Did fertility decline, what was the pattern of decline, and to what extent did fertility fall in response to the changes thus far discussed? 
From a remarkably low level during the 1937-41 period, the pattern of fertility change in Red Sky is one of recovery to Liberation, followed by the sort of fertility decline that the theory of demographic transition would lead us to expect given the rapid urban and industrial development that took place in Tianjin after 1949 (Table 13). After the data are disaggregated, however, the pattern becomes less straightforward. Figure 6 shows fertility change year by year from 1936 to the end of 1981, a pattern that no longer reflects regular, consistently falling fertility from the late 1930s.

Fertility was low in Red Sky during the decade or so before Liberation. Between 1938 and 1941, total fertility dropped from three or four children per woman to only two. After Liberation fertility approached five children per woman, surpassing pre-Liberation levels. From 1958 through 1960 there was another fertility drop. A short-lived and modest recovery ensued, but from 1962 there was another sharp decline until about 1966. This one brought fertility to a level even lower than during the decade or so before Liberation. The people of Red Sky had attained a level of fertility below replacement. Although there was some recovery between 1967 and 1969, fertility remained low even by pre- 1949 standards. The decline resumed after 1969 until about 1976, after which there was a gradual and modest upward shift. In 1976 two major earthquakes ravaged Tianjin and killed at least 20,000 people, many of whom were children. The sharp rise in fertility immediately thereafter "has been explained, in part, as compensation for the loss suffered in the 1976 earthquake" (Lyle 1980:566-67). From 1966 to the end of 1980 , fertility remained below replacement. In 1981 total fertility was 1.36 , slightly lower than Tianjin's overall 1.65 (Banister 1984:250).

I also analyzed infant mortality in Red Sky and found that it has fallen steadily and sharply since even before Liberation (Figure 7). The sharp decline in infant mortality from 1931 to 1932 or 1933 and the increase from 1972 could both be artifacts of small numbers, but the precipitous rise from 1937 to 1939 is probably real. It corresponds to a period of unusual difficulty, with the peak occurring during the major flood of 1939. The drop in infant mortality since Liberation could be seen to be as much the result of the fact that more children were first borns, and therefore possibly healthier and better cared for, as of an overall decline in mortality. When I compared the mortality of first borns with that of other infants, however, the data indicated the same pattern of decline, interrupted only during 1937-43, when Tianjin suffered famine, violence, and flood. However, whereas infant (and child) mortality fell steadily and sharply from about 1943, reducing some of the pressure on parents to have children, the drop in fertility during the same period was neither steady nor continuous. There were even periods during which falling infant mortality was accompanied by rising fertility. 
Table 13. Fertility, by five-year intervals: Red Sky, 1937-81

\begin{tabular}{|c|c|c|c|c|c|c|c|c|c|}
\hline \multirow[b]{2}{*}{ Interval } & \multicolumn{6}{|c|}{ Age-specific fertility rate } & \multirow{2}{*}{$\begin{array}{c}\text { General } \\
\text { fertility } \\
\text { rate }\end{array}$} & \multirow{2}{*}{$\begin{array}{l}\text { Total } \\
\text { fertility } \\
\text { rate }\end{array}$} & \multirow{2}{*}{$\begin{array}{c}\text { Mean } \\
\text { marriage } \\
\text { age }\end{array}$} \\
\hline & $15-19$ & $20-24$ & $25-29$ & $30-34$ & $35-39$ & $40-44$ & & & \\
\hline $1937-41$ & 28 & 147 & 170 & 131 & $53^{*}$ & $29^{*}$ & 89 & 2.8 & 19.2 \\
\hline $1942-46$ & 44 & 147 & 173 & 143 & 93 & $35^{\star}$ & 110 & 3.2 & 20.3 \\
\hline $1947-51$ & 38 & 191 & 193 & 173 & 124 & 64 & 142 & 3.9 & 20.9 \\
\hline $1952-56$ & 52 & 211 & 227 & 199 & 132 & 68 & 166 & 4.4 & 22.7 \\
\hline $1957-61$ & 16 & 192 & 247 & 168 & 99 & 37 & 135 & 3.8 & 23.3 \\
\hline $1962-66$ & - & 125 & 192 & 125 & 72 & 34 & 91 & 2.7 & 25.7 \\
\hline 1967-71 & 3 & 46 & 222 & 85 & 28 & 2 & 60 & 1.9 & 26.1 \\
\hline $1972-76^{a}$ & - & 14 & 162 & 75 & 19 & 3 & 52 & 1.6 & 26.7 \\
\hline $1977-81^{a}$ & - & 6 & 140 & 93 & 28 & 3 & 44 & 1.3 & 26.9 \\
\hline
\end{tabular}

* based on $<100$ woman-years.

a. Adjusted to compensate for the exclusion of never-married women from the universe. Fertility during last decade is therefore exaggerated. Age at marriage has been rising. As a result, only married women of ages 15-19 and 20-24 at risk of conception are included. The data say nothing about their unmarried counterparts. 


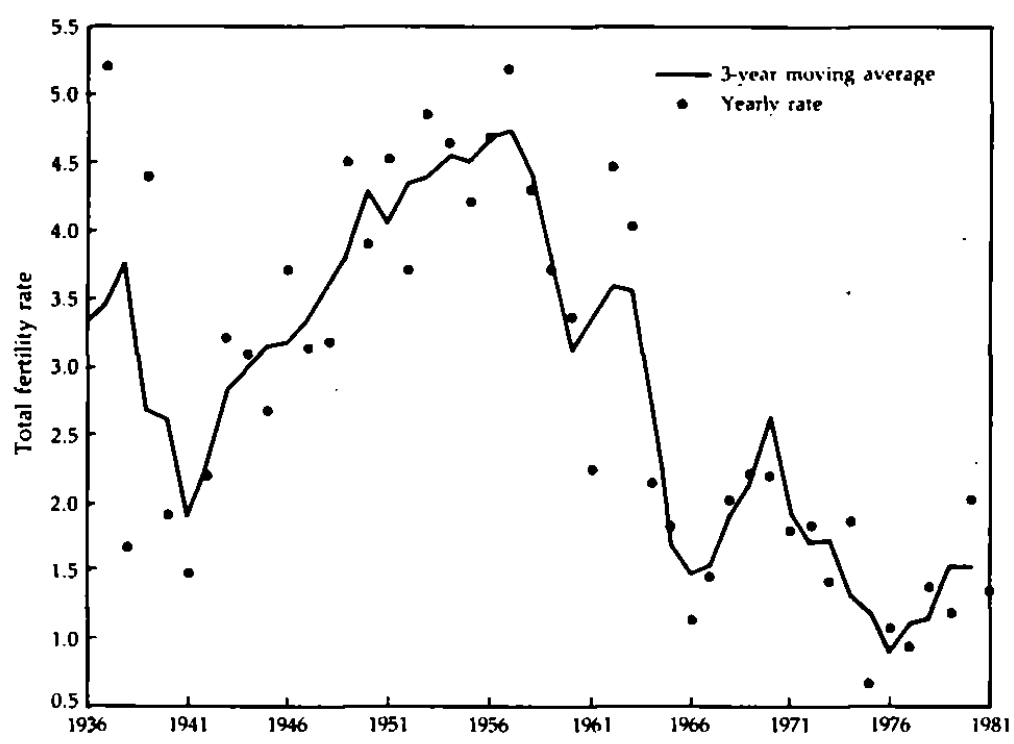

Figure 6. Total fertility: Red Sky, 1936-81 (three-year moving average and yearly rate)

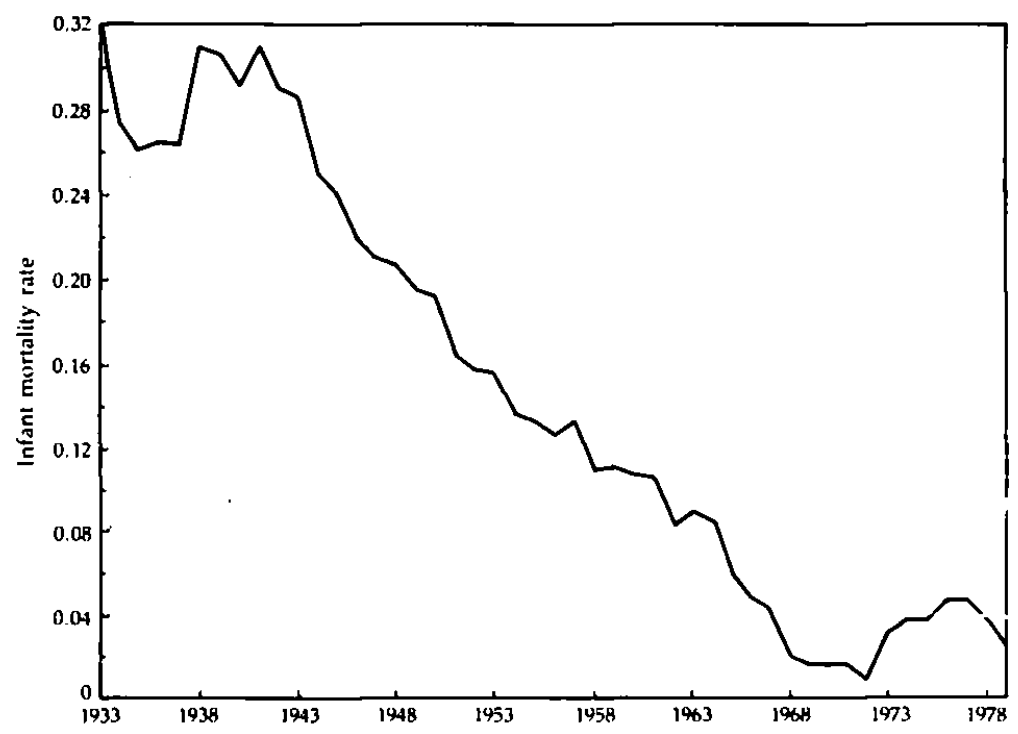

Figure 7. Infant mortality: Red Sky, 1933-79 (five-year moving average) 
Examining the pattern of fertility change, then, leads to the conclusion that "modernization theory" and the model of demographic transition, which are essentially derived from the experience of now developed societies, provide an inadequate basis for anticipating the changes that occurred in Red Sky. The changes in fertility cannot be accounted for simply by increasing access to education, growing involvement of women in the work force, and developing independence of the conjugal unit. Nor can it be explained as a simple function of falling infant mortality, although this factor undoubtedly did contribute to substantially shorter birth intervals and a rise in fertility.

Increasing marriage age also had a negative effect on fertility, but it too cannot account for the pattern of fertility decline. Whereas the rise in age at marriage was gradual and reasonably constant, fertility decline was neither. Fertility increased during 1941-57 as marriage age rose. It increased again during 1960-1963, and again during 1966-69-both periods during which the mean age at marriage continued to go up. Another indication that changing age at marriage was not responsible for modulations in fertility is that changes in the fertility of married women closely parallel those of all women (Figure 6 and Figure 8). Again, the data show an increase

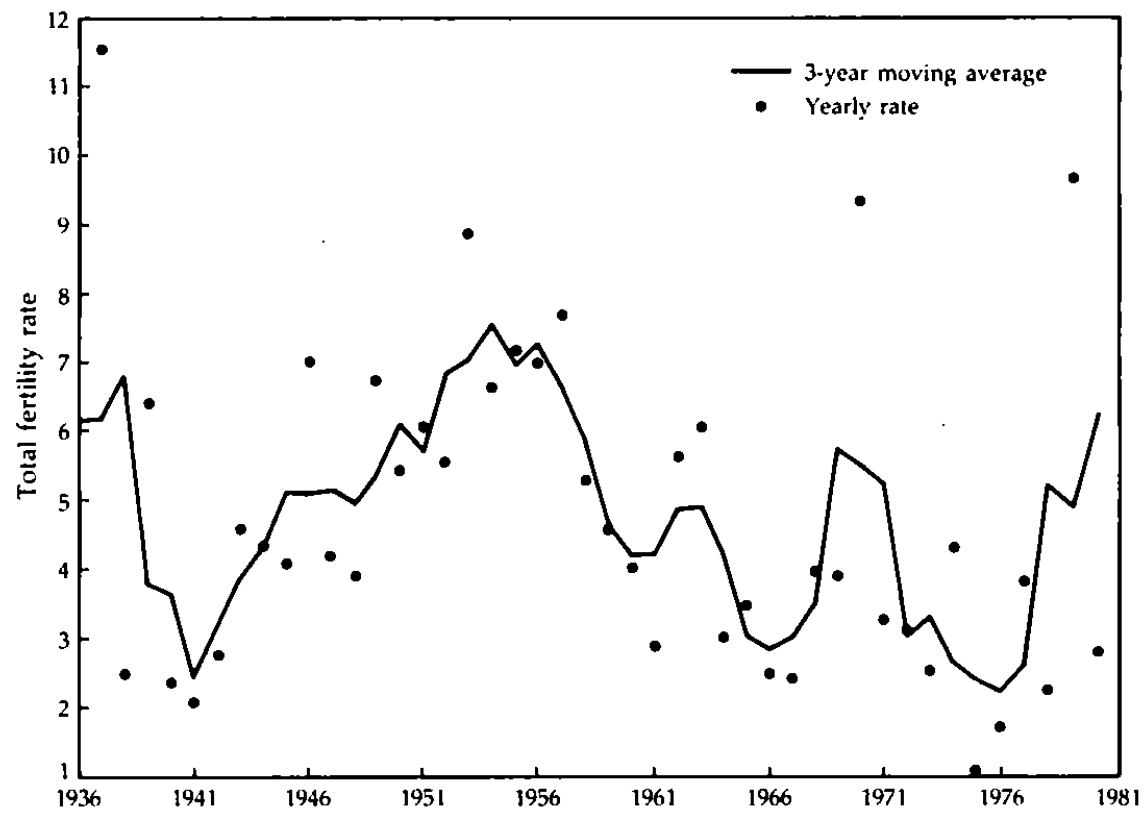

Figure 8. Total marital fertility: Red Sky, 1936-81 (three-year moving average and yearly rate) 
in marital fertility through 1952-56, with a decline thereafter. How shall we account for the peculiar modulations evident in the fertility pattern? It might be useful to begin with the demography-to let changes in fertility signal the important, related changes in society. In my view, what needs to be explained is not the shortening of birth intervals and the rise in fertility after 1949, but the low fertility before. The post-Liberation fertility rise, in this view, was essentially a recovery.

\section{Pre-Liberation Tianjin: context for low fertility}

During the decade or so before 1949 , fertility was apparently low in many Chinese cities. Data from Chengdu indicate that the mean number of births to women of ages 56 and over was 4.49 (Five Cities Family Research Project Group 1985:235). This figure is analogous to my figure of 4.7 for total marital fertility for women of ages 55 and over. Retrospective surveys in two Beijing districts also indicate low fertility for women born in 1914 and 1920. On the basis of published data, I calculate total fertility rates (ages 15-44) of 4.4 and 4.4 for Xicheng District women, and 4.9 and 3.8 for Haidian District women born in those years. The total fertility rate for Red Sky women born before 1920 was 3.6. The fertility rates of subsequent cohorts in Xicheng and Haidian are also not very different from those in Red Sky. Total fertility was 4.0 and 3.4 in Xicheng and Haidian respectively for women born in 1930; in Red Sky total fertility was 3.2 for women born during 1927-38. Women born in 1940 had rates of 2.0 and 2.8 in Xicheng and Haidian respectively, and those born in 1946 had rates of 1.4 and 1.6. The analogous rate for Red Sky women (born during 1939-50) was 1.9 (Liu Juyu 1983:22; Ye Yanru 1983:44).

Because I had not anticipated the low fertility of Red Sky women during the pre-Liberation period, my interviews and questionnaires did not include questions that would have allowed me to go directly to the causes. Nonetheless, enough is known about life in Tianjin in the years before Liberation to approach the question indirectly. Five factors in particular could well have contributed to a low level of fertility: (1) frequent and substantial spousal separation, (2) periodic famine, (3) high morbidity, (4) high infant and adult mortality, and (5), in view of the difficult living conditions that prevailed, deliberate attempts to limit the number of children born (all parities).

Fertility-depressing conditions were particularly acute from 1939, when a flood ravaged Tianjin and the surrounding countryside, producing a famine in 1940 and 1941. The situation improved little during the ensuing war years up to about 1946. Even before Japanese troops took control of the city in 1937, working and living conditions were not conducive to high fertility. The urban population was disproportionately male, as wives and children commonly remained in the countryside. Women who lived in the city 
suffered periodic famine and chronic poor health. Finally, city workers, both male and female, labored under incredibly poor conditions, suffering from exhaustion, illness, and separation from their spouses and loved ones.

From the time they took control of Tianjin, the Japanese, plagued by the Communist Eighth Route Army activities in the countryside around Tianjin, monitored and controlled movement within the city and also between the city and the countryside. Traveling to and from work was therefore risky and time-consuming. For many it was safer and more convenient to live at the factory. Visiting one's family in the countryside was even more difficult and dangerous because the Japanese were especially suspicious of people moving between the city and the rural areas. The Japanese also. made frequent punitive expeditions and sorties to search either for the enemy or for labor to exploit in fighting the enemy. They sent troops to oversee harvests and collect grain taxes reportedly amounting to as much as 50 or 60 percent of harvest. As a result rural life and economy were seriously destabilized (Hershatter 1982:128, 185-86). One response to Japanese pressures was to try to dodge the Japanese by remaining in the countryside. Another was to leave the countryside altogether to live under the Japanese in garrison towns or in the city. Such migration usually involved spousal separation.

Much of what we know of life in Tianjin before Liberation is derived from interviews and general historical accounts. Little information is available in the form of systematic social surveys, apart from a useful 1926 study, conducted by Chinese researchers, of workers in two "model" factoriesthe Chiu Ta Salt Refinery and the Pacific Alkali Works-in Danggu, a town some 30 miles southeast of Tianjin. These factories were not typical, however. As the author of the published account indicates, "such a solicitous spirit shown for the well-being of their workers, it must be admitted, is but rarely met with in factories in this country" (Lin 1928:viii). Even so, the description of conditions in these factories might well have shocked Western readers of that time.

Workers at the Chiu Ta Salt Refinery were mainly young men; 75 percent were between the ages of 20 and 35 . Most lived in factory quarters; few had families in Danggu. A large proportion of resident workers (59 percent) and of those with families in Danggu ( 39 percent) had been agricultural workers before coming to the refinery ( $\operatorname{Lin} 1928: 53,70$ ). Even before the Japanese took control of the area, workers commonly lived apart from their families, and movement into the city often resulted more from push factors, i.e., poverty and disorder in the countryside, than from some intrinsic attraction of the city or town (Lin 1928:53-54). Even before the 1930s, then, fertility may have been adversely affected by spousal separation and poverty. 
Although 95 percent of workers with families in town were married, town-dwelling workers constituted only about one-quarter of the factory work force. Fifty-two percent of the far more numerous dormitory residents were also married (Lin 1928:55-58, 71-72). Thus, although a substantial proportion of workers were married, they had little access to their spouses. Similarly, of fifty resident workers surveyed at the Pacific Alkali Works, 40 percent had spouses living elsewhere (Lin 1928:101). Such a situation is hardly conducive to high fertility.

Although the two factories described in the 1926 study were models of industrial enlightenment at the time, the surveys indicate difficult and unsanitary working and living accommodations. From 1916 to 1927 at least, common laborers worked twelve hours a day, and skilled workers ten. Opportunities for home visits were rare (Lin 1928:22, 24). Despite unusually beneficent management at the two plants, illness and accidents were common, especially diarrhea, colds, skin inflammations, and burns (Lin 1928:40). Unhealthful, unsafe working conditions were particularly characteristic of the Pacific Alkali Works.

Conditions were even worse in more typical factories in the years before Liberation. The worker's life was one of unmitigated drudgery and fatigue, especially during the Japanese occupation and the subsequent civil war (Hershatter 1982:138-39). Apart from long, hard hours, workers had to endure hazardous, unhealthful conditions on the job and, often, dangers outside the workplace as well. As one of the informants in Gail Hershatter's study of pre-Liberation factory workers put it, "we were working fifteen, sixteen hours a day, and on the streets the Japanese were often seizing people for forced labor, so we didn't dare to go out" (Hershatter 1982:145). Marriage was not easy, visits to family were infrequent, and rarely were workers in a position to live away from their factories with their spouses (Hershatter 1982:134, 148, 150).

Although most migrants and urban workers were males, there were some female workers. Women, however, entered Tianjin's textile mills late and in small numbers. In 1929 only 9.14 percent of the cotton mill work force was female ( 13 percent if child labor is included). It was not until the Japanese took control of Tianjin that the proportion reached 39 percent; in 1947 women still constituted barely half of all mill workers (Hershatter 1982:188).

Most women employed in the mills during the 1920s were young and either unmarried or, if married, willing to live in dormitories apart from their spouses, as most mills had rules forbidding marriage. Women who married secretly and subsequently became pregnant were usually quickly discovered and promptly fired (Hershatter 1982:193-94). Once inside the mill, women faced ten-to-twelve-hour days in perpetual motion, under a 
light mist. Poor diet and unhealthful working conditions combined to make them highly susceptible to illness. Lung and eye problems were common. Disease spread quickly in the overcrowded, poorly ventilated dormitories, and industrial accidents were commonplace. Working-class neighborhoods had neither water nor sewage disposal. There too illness was commonplace and mortality high (Hershatter 1982:235-42, 378).

My data support Hershatter's findings that conditions were especially difficult during the Japanese occupation. Poor working conditions and fatigue were compounded by severe malnutrition to the point of starvation. The situation became desperate during and after the flood of 1939. Although the supply of food increased somewhat at the end of the occupation, partly because of flour imports from the United States, rampant inflation undermined the workers' buying power and encouraged hoarding by merchants. Hunger therefore continued. Excerpts from interviews I conducted in Tianjin convey something of the horror of those times. These recollections give evidence of illness and starvation, spousal separation, anxiety, and fearcircumstances clearly not conducive to even a moderate level of fertility.

I was born and raised in Tianjin's North District. We were altogether eight people, my parents, five sisters, and myself. My youngest sister had to be sold to offset our poverty. My second youngest sister died early. Mother died at 39 in 1930 . . . . Father, a wagon puller, died of throat cancer half a year later. He managed to find a mother-in-law for me before he died, and I left home to join her shortly before his death. ...

During those years we were constantly afraid. People were searched everywhere by the Japanese. . . My husband initially lived apart from me, in Earthwall, where he worked as a long-term field laborer. When the landlord went bankrupt my husband found himself without employment. He tried to do some small business in the city, selling flowers and ice cream. After the Japanese arrived he couldn't even do that. They took him away to do labor for them. Things got a lot worse in 1939, when there was a great flood in Tianjin. Once again my husband was without work. He tried to work as a carrier on the river piers. . . . One day he dropped his burden into the water while carrying it off a ship. When he jumped in to retrieve it he was struck by a large, heavy piece of lumber. . . . His fingers were broken and mutilated and, from that time, he could do little work. For two years I washed clothing for the Japanese so we could eat. Then I managed to find a job in the wool factory where I worked until 1952, when I had to withdraw to care for my children. My husband managed to find a job in a textile factory but couldn't hold it because of his physical problems. In the end he became a street sweeper-C.K. Huang 
Conditions in Tianjin were especially difficult between 1937 and 1945, during which time the Japanese conducted nine campaigns to consolidate their control. Food shortage was a major problem. What flour was available was increasingly adulterated and, by 1940 , one could find no flour at all. In the summer of 1939 there was a great flood. Water rose to the height of a man or even higher in some places. There were dead bodies floating everywhere. . . . Hunger stalked the city and surrounding countryside, driving people to extremes. There was looting and stealing. It took about two months for the waters to subside. During that time we ate anything we could find. . . The stench of death was everywhere.

We were all afraid of diseases, but the Japanese method of dealing with the problem frightened us as much. . . . The Japanese frequently erected roadblocks looking for people who were ill. People suspected of being ill were carted away in trucks. No one knows what became of them. These health checks were especially common during the summer of 1939 and people were so afraid of being taken away that they were reluctant to leave their homes. You could never know whether or not you would return. . . .

Between 1941 and 1944 the Japanese conducted their seventh and eighth pacification campaigns. During that period even maize flour was not to be found. We ate flour made of broad beans, sorghum, and peanuts. Eventually that too was adulterated with wood shavings and even with stones. . . . In 1944 there was nothing at all to eat. We ate horse fodder-the bran or shells of peanuts mixed with yellow beans. Even for such foods prices soared out of sight. In the course of a single day food prices could rise four or five times. . . .

Conditions were even more difficult in the countryside, where people were eventually reduced to eating the bark of trees. For about one year after the flood there were no harvests and people starved. In addition, the Japanese, concerned about activities of the Communist Eighth Route Army in the countryside, launched periodic searches and punitive expeditions, burning villages and killing people. Because conditions were so bad in the countryside, many rural people preferred to take their chances in the city or town. Many young men left their wives and children in the countryside and came to stay with friends or relatives in the city. Those discovered during nighttime house inspections were carted away as possible resistance fighters.-M.R. Liu

\section{Tianjin after Liberation: political controls on fertility}

Although marriage was legally and administratively delayed shortly after Liberation, birth intervals nonetheless became shorter and fertility rose. Women married later but had their children in quicker succession. Increasing access to education and increasing involvement in work outside the home does not seem to have curtailed childbearing during this early pe- 
riod. In fact, it could be argued that, had the age at marriage not been delayed and had women continued to devote their energies exclusively to domestic chores, fertility might actually have been even higher.

\section{Post-Liberation fertility trends}

According to one source (Pao and He 1960:62-63), only 7.5 percent of Tianjin's population growth in 1949 was the result of natural increase-the difference between birth and death rates. By 1953, however, the proportion attributable to natural increase had grown to 31.8 percent and, by 1956, to 35.1 percent. Much of Tianjin's growth was caused by an influx of rural people that was stimulated by growing industry. It is the natural increase, though, that most interests us here.

It resulted from falling mortality. That mortality declined is no great surprise. Not only had peace come to Tianjin, but also immediate steps were taken to stabilize the city's economy and improve living conditions. Sanitation and health improved, and there is evidence of substantial improvements in consumption. One source compares the situation for $\mathbf{4 5 5}$ workers in 1956 with data collected on the families of 132 craftsmen in 1928-29:

We shall cite for comparison data on the life of $\mathbf{4 5 5}$ workers' families in 1956. Every member of a working family on the average consumed the following annually: high quality food $=263.8$ chin, which is 103 chin more in comparison with the previous data; low quality food = 74.5 chin, i.e., 128.5 chin less than before; meat $=12.36$ chin, or 5.15 chin more; eggs $=71$, i.e., 69 more; fish $=20.15 \mathrm{chin}$, i.e., $13.46 \mathrm{chin}$ more; sugar $=2.76 \mathrm{chin}$, or $2.74 \mathrm{chin}$ more, and fabric $=27.28 \mathrm{ch}$ 'ih, or 17.28 ch'ih more. [One chin, or catty, equals 34.28 grams or 1.10 pounds; one ch'ih equals one-third meter or approximately 1 foot.] Every man had an average of 3.38 square meters of dwelling area, or 0.45 square meters more than prior to Liberation. Most of the workers now live in the newly constructed communal houses rather than in mud or clay houses, which prevailed before (Pao and He 1960:58, 67).

An indirect indication from the Red Sky data that improvements in living conditions had a felicitous effect on health is that the age at first menses declined; the mean ages at first menses for women of ages 45-49, 40-44, $35-39,30-34$, and $25-29$ were $15.9,15.5,14.9,14.9$, and 14.7 years respectively.

Improvement in overall health and the decline in infant mortality after Liberation are changes that might be expected to have contributed to higher fertility, all other things being equal. Yet, whereas the level $(M)$ of marital fertility in Red Sky increased from 0.49 in 1937-41 to 0.92 during 1967-81, total marital fertility began falling in the mid-1950s after an initial period of increase that started in 1941 (Figure 8). Looking at the data on marital 


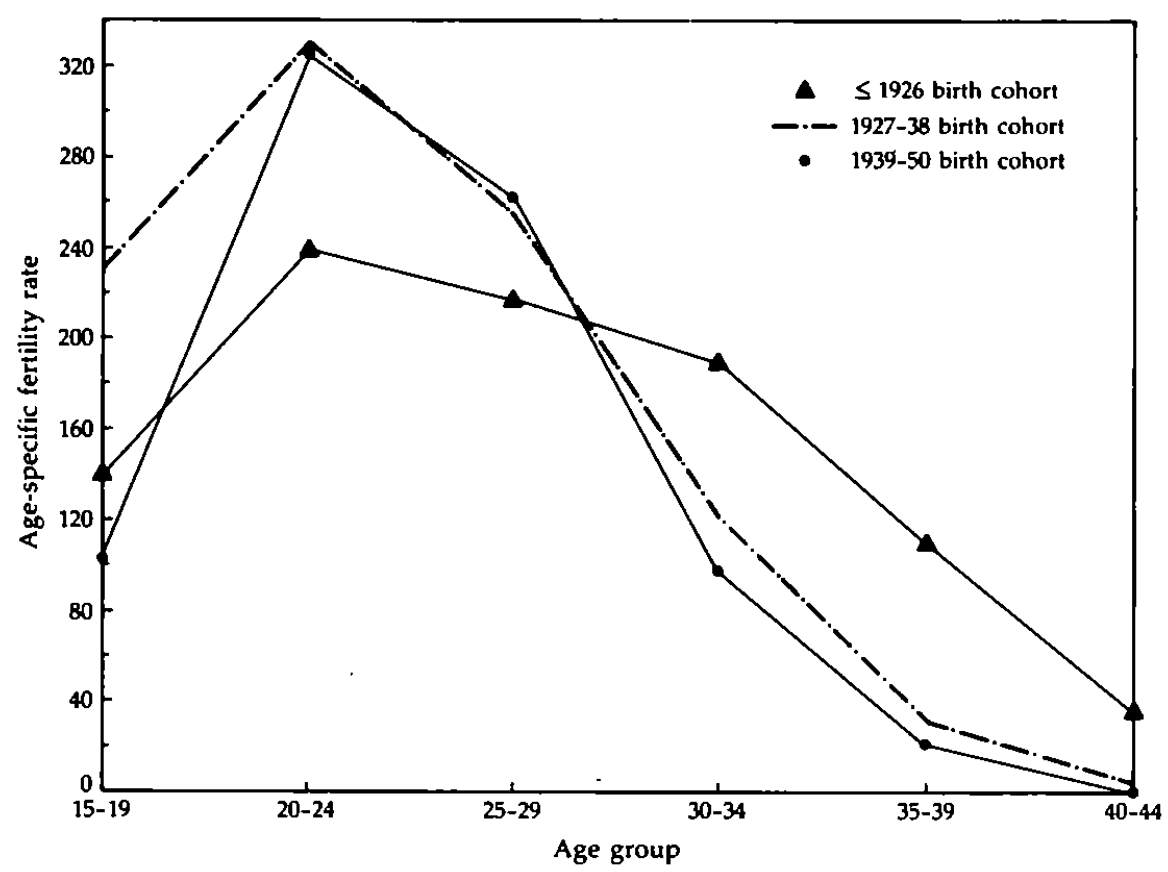

Figure 9. Age-specific marital fertility, by birth cohort: Red Sky

fertility in relation to birth cohorts helps to make sense out of this apparent contradiction (Figure 9). ${ }^{6}$ The marital fertility of women who were in their peak childbearing years just after Liberation (those born during 1927-38) rose dramatically during their younger years, compared with women in the earlier, pre-Liberation cohort. Even though the average age at marriage was increasing, many women born during 1927-38 married young (at ages 15-19). Their initial marital fertility was higher than that of earlierborn women, producing a higher level of fertility. They ended their childbearing earlier, however, to a large extent cancelling out their higher early fertility. The most important difference between women born during 1939-50 and those born earlier is that they exhibit markedly lower fertility from ages 25 to 29 . This is because women in this cohort were most subject to programs and policies intended to delay marriage and to limit childbearing during marriage.

Could it be that the sharp rise in early marital fertility following Liberation is more apparent than real, an artifact of the way age-specific fertility

6. The peak reproductive ages ( 20 through 29$)$ for women born before 1927 occurred before Liberation. For those born during 1927-38 it was after Liberation but before the Cultural Revolution. The peak for women born during 1939-50 occurred after 1966. 
Table 14. Duration-specific legitimate fertility, by years married and birth cohort (first marriage): Red Sky, December 1981

\begin{tabular}{|c|c|c|c|}
\hline \multirow[b]{2}{*}{ Years married } & \multicolumn{3}{|c|}{ Duration-specific fertility rate } \\
\hline & $\begin{array}{l}\leq 1926 \\
\text { birth cohort }\end{array}$ & $\begin{array}{c}1927-38 \\
\text { birth cohort }\end{array}$ & $\begin{array}{l}\geq 1939-45 \\
\text { birth cohort }\end{array}$ \\
\hline$<1$ & 40 & 75 & 149 \\
\hline 1 & 255 & 480 & 591 \\
\hline 2 & 242 & 295 & 246 \\
\hline 3 & 191 & 267 & 214 \\
\hline 4 & 220 & 306 & 157 \\
\hline 5 & 201 & 324 & 183 \\
\hline 6 & 243 & 200 & 124 \\
\hline 7 & 228 & 200 & 96 \\
\hline 8 & 229 & 241 & $82^{\star}$ \\
\hline 9 & 193 & 135 & $68^{\star}$ \\
\hline $10-14$ & 171 & 102 & 22 \\
\hline 15-19 & 111 & 24 & - \\
\hline$\leq 20$ & 57 & 5 & - \\
\hline
\end{tabular}

* Based on $<100$ woman-years.

is calculated? Could the increase in fertility for women of ages 15-19 simply result from the fact that because women married later-closer to 19 than to 15-they contributed fewer years to the calculated rate? One way to answer these questions is to look at yet another measure of fertility, the duration-specific legitimate fertility rate, which analyzes fertility not by age but by length of time married. If the increase in fertility was real, regardless of age at marriage, women married the same length of time in the various cohorts should have different fertility rates. A comparison of the first two cohorts of women (Table 14) shows that for any duration of marriage up to and including five years, women born during 1927-38 had substantially higher fertility than others. Since women born during 1939-50 were under special pressure to curtail births, we would expect them to have had their first children early in marriage and the lowest fertility thereafter. Their higher fertility should therefore be evident only during the first year or so of marriage. The results are ambiguous for the second year of marriage, but we do find that these women had the highest rate of fertility during the first year.

The increase in age at marriage conceivably could have contributed to the higher early fertility of the post-Liberation cohort in another way. It is possible that women who marry later are more fertile simply because they are older when they begin having children. Table 15 compares the total first marital fertility (ages 30-44) of women in the three cohorts by age at marriage. It shows that, in all cohorts, the relationship between age at 
Table 15. Age-specific fertility in first marriage among women 30-44 years of age, by birth cohort and age at marriage: Red Sky, December 1981

\begin{tabular}{|c|c|c|c|c|c|c|c|}
\hline \multirow[b]{2}{*}{ Birth cohort } & \multicolumn{6}{|c|}{ Age-specific fertility rate } & \multirow{2}{*}{$\begin{array}{l}\text { Total marital } \\
\text { fertility rate }\end{array}$} \\
\hline & $15-19$ & $20-24$ & $25-29$ & $30-34$ & $35-39$ & $40-44$ & \\
\hline \multicolumn{8}{|l|}{$\leq 1926$} \\
\hline Married age 15-19 & 147.2 & 215.1 & 175.1 & 165.7 & 101.0 & 24.1 & 1.45 \\
\hline Married age $20-24$ & - & 265.9 & 260.9 & 205.2 & 86.7 & 23.6 & 1.57 \\
\hline Married age 25-29 & - & - & 338.0 & 226.1 & 125.5 & 54.8 & 2.03 \\
\hline \multicolumn{8}{|l|}{$1927-38$} \\
\hline Married age 15-19 & 246.1 & 302.0 & 207.8 & 102.4 & 8.0 & - & 0.55 \\
\hline Married age $20-24$ & - & 363.1 & 270.0 & 90.0 & 17.1 & 7.3 & 0.57 \\
\hline Married age 25-29 & - & - & 295.1 & 200.0 & 58.3 & 8.9 & 1.34 \\
\hline \multicolumn{8}{|l|}{$1939-50$} \\
\hline Married age $15-19$ & $169.0^{\star}$ & $240.0^{\star}$ & $280.0^{\star}$ & $40.0^{\star}$ & - & - & 0.20 \\
\hline Married age $20-24$ & - & 419.3* & 150.0 & 30.6 & $11.5^{*}$ & - & 0.21 \\
\hline Married age $25-29$ & - & - & 323.3 & 108.9 & 21.9 & - & 0.65 \\
\hline
\end{tabular}

* Based on $<100$ woman-years. 
Table 16. Duration-specific legitimate fertility during first four years of marriage, by age at marriage and birth cohort: Red Sky, December 1981

\begin{tabular}{lcc}
\hline & \multicolumn{2}{c}{ Duration-specific legitimate fertility rate } \\
\cline { 2 - 3 } Age at marriage & $\begin{array}{c}\leq 1926 \\
\text { birth cohort }\end{array}$ & $\begin{array}{c}1927-38 \\
\text { birth cohort }\end{array}$ \\
\hline$\leq 19$ & 151 & 249 \\
$20-24$ & 202 & 318 \\
$25-29 a$ & 282 & 277 \\
\hline
\end{tabular}

a. The difference in rates for this age group is not statistically significant at the 0.05 level.

marriage and fertility was in the direction suggested: women who married at ages 25-29 had the highest fertility rates, and those who married at ages 20-24 had higher fertility rates than those who married younger. As Table 16 indicates, however, even when age at marriage is controlled for, durationspecific fertility rates during the first four years of marriage are generally higher for women born during 1927-38 than for those born earlier. I have concluded, then, that the increase in early fertility for women born during 1927-38 was neither a product of the way age-specific fertility is calculated nor the simple result of later marriage. The increase in duration-specific fertility suggests that women in the second cohort achieved the same level of fertility as pre-Liberation women despite a more marked fertility decline with age. They had as many children as their predecessors but had them sooner. Consistent with this conclusion is the finding that the intervals to each of the first three births decreased (Table 17). The rate and duration of breastfeeding also declined (Figure 10)? Since breastfeeding inhibits conception, this could well have contributed to shorter second- and third-birth intervals; changes in breastfeeding would not account, however, for the documented shorter interval between marriage and first birth.

\section{Introduction of family planning}

Family planning, in the sense of programs specifically intended to limit family size, was first systematically introduced in Tianjin during 1954-57 (Lyle

7. In a separate study done in collaboration with Wang Ching of the Beijing Institute of Food Research, data show that the rate and duration of breastfeeding dropped in Red Sky as women increasingly acquired formal education, as they became involved in full-time work outside the home, as they adopted neolocal postmarital residence, as their income increased, and as their rural origins decreased (Pasternak and Wang 1985:433-66). Data from the Five Cities Project also indicate a decline in the rates and duration of breastfeeding but considerable difference among cities in the degree of change. Compared with other cities, the decline has been less serious in Tianjin (Five Cities Family Research Project Group 1985:548-57). 
Table 17. Mean birth intervals of women in first marriage, by birth cohort: Red Sky, December 1981

\begin{tabular}{|c|c|c|c|c|c|c|c|c|}
\hline \multirow[b]{2}{*}{ Interval } & \multicolumn{2}{|c|}{ Born $\leq 1926$} & \multicolumn{2}{|c|}{ Born 1927-38 } & \multicolumn{2}{|c|}{ Born 1939-50 } & \multicolumn{2}{|c|}{ Born $\geq 1951$} \\
\hline & $\begin{array}{c}\text { No. of } \\
\text { intervals }\end{array}$ & $\begin{array}{c}\text { Mean } \\
\text { (months) }\end{array}$ & $\begin{array}{c}\text { No. of } \\
\text { intervals }\end{array}$ & $\begin{array}{c}\text { Mean } \\
\text { (months) }\end{array}$ & $\begin{array}{c}\text { No. of } \\
\text { intervals }\end{array}$ & $\begin{array}{c}\text { Mean } \\
\text { (months) }\end{array}$ & $\begin{array}{l}\text { No. of } \\
\text { intervals }\end{array}$ & $\begin{array}{c}\text { Mean } \\
\text { (months) }\end{array}$ \\
\hline Marriage to first child ${ }^{a}$ & 211 & 42.0 & 159 & 23.0 & 124 & 15.6 & 57 & 11.7 \\
\hline First to second child & 192 & 41.8 & 155 & 37.0 & 91 & 43.5 & 2 & - \\
\hline Second to third child & 153 & 44.7 & 116 & 38.9 & 17 & - & - & - \\
\hline Third to fourth child & 117 & 38.5 & 63 & 41.9 & 3 & - & - & - \\
\hline Fourth to fifth child & 80 & 39.2 & 27 & - & - & - & - & - \\
\hline Fifth to sixth child & 48 & 43.7 & 3 & - & - & - & - & - \\
\hline
\end{tabular}

Note: Means provided only where number of intervals $\geq 50$.

a. Intervals of less than nine months excluded. 

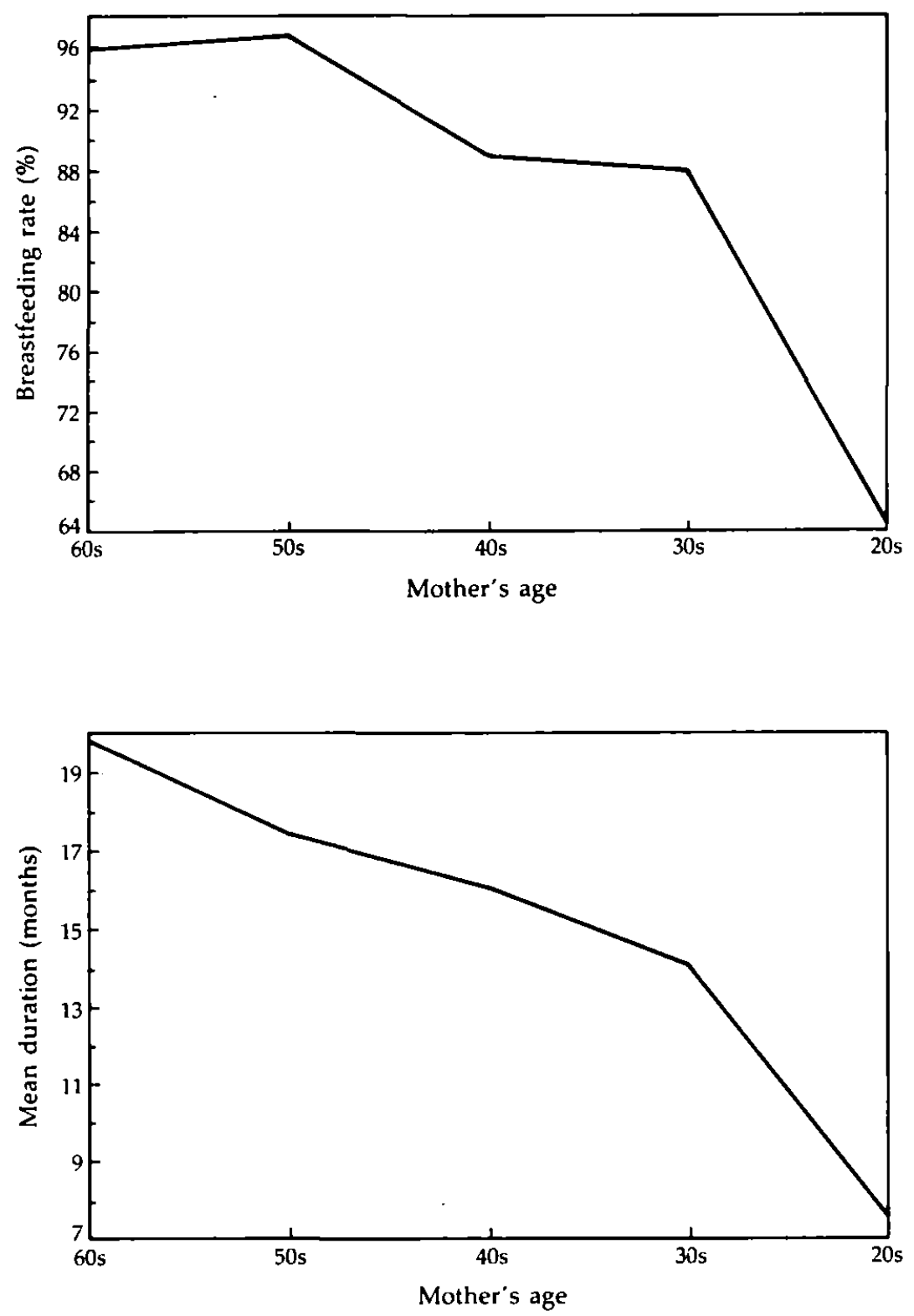

Figure 10. Breastfeeding rate and duration, by mother's age: Red Sky 
1980). The goal of this early effort was more to improve maternal health through family limitation than to limit family size by controlling childbirth. Official support for family planning was demonstrated as early as 1955 with the spread of services and the organization of educational campaigns (Kane 1985:87). The program focused on literate urban dwellers, the goal being to free women for production. During the latter part of 1955, cadres in state agencies and enterprises in Hebei Province became the subject of a family planning campaign. One year later the campaign was extended to all urban dwellers and to industrial and mining workers (Kane 1985:87-88).

In 1958 and 1959, during the earliest years of the Great Leap Forward, the Chinese government changed its position and argued that family limitation was to be avoided and that China's population was not large enough. Labor was mobilized on a massive scale, and attempts were made to "liberate" female labor-to move women out of the home and into the factories. In addition to work done in the factory during the day, evenings were given to the manufacture of steel in so-called "backyard blast furnaces." Spouses were often separated during the day and at night. People came home exhausted at the end of a work day, with little energy for eating and virtually none for sex.

During the "three bad years" from 1959 to 1961, production and commerce came to a standstill and severe food shortages launched massive migrations to the city, migrations that often involved conjugal separation. The sharp rise in mortality that occurred during those years would have conspired with exhaustion, stress, and famine to lower fertility. Ansley Coale reports that excess deaths in China (those above a linear trend) from 1958 to 1963 were about 27 million, when mortality is adjusted for understatement (Coale 1984:7). It is interesting that, although mortality in general soared in China during the "three bad years," the data from Red Sky show no noticeable increase in infant mortality. This may be because the numbers are so small, but it could also indicate that the drop in fertility that occurred during those years was less due to higher infant mortality than to other factors, such as exhaustion, famine, and lowered coital frequency.

The sharp decline in fertility beginning in 1962 had a different cause. By late 1961 the bankruptcy of the Great Leap Forward had become all too evident, and there was a shift to less radical policies and programs. Associated with that shift was a renewed interest in family planning. From 1962 an effective, well-administered family planning program was initiated in Tianjin. Measures were taken to create the kind of infrastructure, and to carry out the sort of mass mobilization, that would ensure effective and systematic family limitation. This time the program was specifically aimed at controlling reproductive behavior to limit family size. 
Fertility fell rapidly in response (Figure 6). The decline was interrupted only during the Cultural Revolution's (1966-76) baby boom, which Red Sky residents attribute to a collapse of administrative and industrial efficiency in the face of political chaos (see Lyle 1980:553-64). Factory efficiency was greatly reduced because workers were constantly involved in political meetings and because discipline crumbled in the wake of purges of cadres and administrators. Production slowed dramatically, leaving workers with free time to spend at home.

Efforts to restore interest in family limitation were renewed by 1970, and fertility once again declined, reaching an all-time low in 1976, the year of a major earthquake. The recovery thereafter was slight. With the fall of the "Gang of Four" in 1976 and the subsequent restoration of less radical policies, couples were actively pressured to avoid having more than two children. Late marriage, single-child families, delayed childbirth, and wide birth spacing for women determined to have a second child were stressed. Birth targets were allocated downward through the administrative hierarchy, from the national level to the work unit. Most units had family planning committees that charged specific individuals with responsibility for implementing family planning policies. During my stay in Tianjin I heard complaints about inequities in the allocation of work-unit birth targets. I was told that, although some units had more newly married people than others, planning was not so detailed and efficient as to take such differences into account. As a result, some work units consistently exceeded their targets whereas others did much better.

Work units created incentives for couples formally to register as singlechild families. Some work units offered couples with one-child contracts a monthly $5 \mathrm{RMB}$ salary supplement, which was to continue until the child reached age 14 . If the couple had a second child they were to return the rewards. Longer maternity leaves were commonly allowed to contract mothers-six months paid leave instead of the normal fifty-six days. A few work units were said to give special consideration to contract couples in the allocation of housing. During the time I was in Tianjin, however, such allocations were not commonplace. $I$ also found no evidence that children of contract families had special access to nurseries or other schools, and it is still too early to know whether they will actually enjoy priority in the assignment of jobs, as is sometimes claimed.

In 1979 municipal authorities in Tianjin and Beijing publicized policies designed to discourage third- or higher-parity births. According to published regulations, the parents of third-parity infants were to be docked 10 percent of their annual salary until the child reached age 14 . For parents of fourth- and fifth-parity children, salaries would be reduced by 15 and 20 percent respectively. 
In Tianjin couples were pressed to wait four years before having a second child. Those who did not comply were, in theory at least, to be docked 10 percent of their joint monthly salary (Croll 1985:196; Lyle 1980:555-56). Even if couples were unwilling to sign single-child contracts, a second conception meant repeated visits from work-unit cadres, who came to urge abortion. Couples who exceeded two births drew more substantial criticism and pressure, and registration of such births was often delayed for several months, during which time rationing rights were withheld.

Enforcement of the two-child limit was still not strict, however, during the time I was in Tianjin. Reports from China since my departure, letters from friends still in Tianjin, and information obtained during a visit to that city indicate that family limitation has been more systematically and forcefully pursued since 1981 . Stronger pressure is now reportedly exerted to discourage couples from having more than one child. Couples who are determined to have a second child are pressed to delay for forty-eight months. Women who are pregnant with a second child are pressured to seek an abortion, and sterilization is reportedly actively urged for all women who have had two children (see Bongaarts and Greenhalgh 1985).

\section{Effectiveness of family planning efforts}

Although family planning efforts were less strictly enforced when I was in Tianjin, they were nonetheless effective; by 1976 fertility had reached an all-time low. The success of the new family planning efforts can also be seen from an analysis of the sibling positions of children born since 1949 (Figure 11). Virtually all children born since 1979 are first children; very few second children and no third children have been born in recent years. Data from the sample census indicate a high proportion of first-born infants for the city generally: 78.5 percent of all children born in 1981 were first borns, 16.2 percent were second children, and 5.3 percent were third- or higherparity births (Banister 1984:250; see also Lyle 1980:562).

I mentioned earlier that rising age-specific marital fertility rates resulted from a shortening of some birth intervals and that the most important interval in this regard was the first, that between marriage and first birth. The second birth interval decreased around the time of Liberation but then began to increase again in 1952. With the institution of more systematic family limitation efforts in 1962, the second birth interval lengthened substantially, and in recent years, with the increasing emphasis on single-child families, the second interval has lengthened even more. That the second birth interval has been increasing in Red Sky even as the rate and duration of breastfeeding has been declining further indicates the effectiveness of the family planning efforts. 


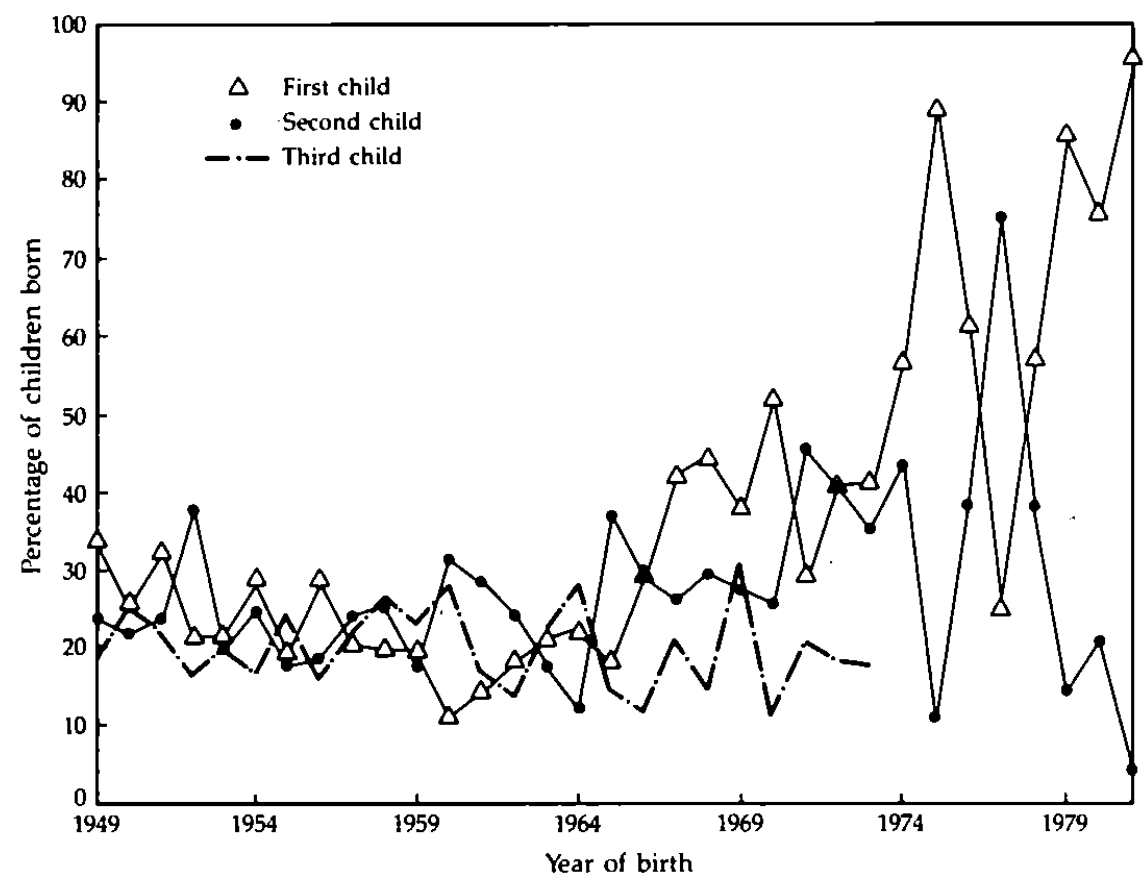

Figure 11. Children in Red Sky, by sibling order and year of birth: 1949-81

Parity progressions also reflect the influence of political and economic changes (Table 18). As with the earlier finding that fertility was low in preLiberation Tianjin, the data on parity progressions show an unusually high proportion of women having no children at all among those married from 1927 through 1941. The proportions at each parity are also lower before 1942 than after. The proportions having more than two children decline beginning with the 1947-51 marriage cohort, suggesting some parity-specific attempt to limit childbirth. We note a sharp drop in the proportion of 1972-76 marriage cohort women having a second child.

Family planning efforts have reportedly been more effectively implemented in Shanghai and in Beijing (Croll 1985:200; Kane 1985:95; Tien $1985: 122,126-27)$. It is not surprising to discover, then, that fertility rates are somewhat higher in Red Sky than in those cities. Data from urban Shanghai indicate a somewhat higher proportion of first-born and a lower proportion of second-born children in 1978-79. In Shanghai 80 percent of all children born from October 1978 to September 1979 were first-parity (Gu Xingyuan et al. 1981:231); in Tianjin the proportion was only 71 percent for the two-year period 1978-79. Also consistent with the evidence for lower fertility and more effective family planning in Beijing are data suggest- 
Table 18. Parity of women, by year married: Red Sky, pre-1926́ to 1981

\begin{tabular}{|c|c|c|c|c|c|c|c|c|c|c|c|}
\hline \multirow[b]{2}{*}{ Year married } & \multirow[b]{2}{*}{ Number } & \multicolumn{10}{|c|}{ Percentage achieving each parity } \\
\hline & & 0 & 1 & 2 & 3 & 4 & 5 & 6 & 7 & 8 & 9 \\
\hline$\leq 1926$ & 26 & - & 100 & 96 & 81 & 54 & 35 & 31 & 19 & - & - \\
\hline $1927-31$ & 24 & 13 & 88 & 75 & 54 & 50 & 33 & 25 & 8 & - & - \\
\hline $1932-36$ & 43 & 8 & 93 & 72 & 58 & 46 & 37. & 23 & 12 & 7 & - \\
\hline 1937-41 & 56 & 11 & 89 & 84 & 70 & 61 & 41 & 25 & 7 & - & - \\
\hline $1942-46$ & 86 & 6 & 94 & 88 & 80 & 66 & 44 & 21 & 11 & 2 & 1 \\
\hline $1947-51$ & 73 & 5 & 95 & 89 & 74 & 52 & 27 & 4 & - & - & - \\
\hline $1952-56$ & 70 & 4 & 96 & 93 & 79 & 36 & 7 & - & - & - & - \\
\hline 1957-61 & 53 & 1 & 98 & 89 & 45 & 19 & 2 & - & - & - & - \\
\hline 1962-66 & 27 & 7 & 93 & 89 & 37 & - & - & - & - & - & - \\
\hline 1967-71 & 57 & 2 & 98 & 84 & 5 & - & - & - & - & - & - \\
\hline $1972-76$ & 38 & 3 & 97 & 50 & - & - & - & - & - & - & - \\
\hline 1977-81 & 94 & 25 & 75 & 1 & - & - & - & - & - & - & - \\
\hline
\end{tabular}


ing greater use of contraceptives there. According to one survey, the percentages of women born in 1920,1930,1940, and 1946 who had used contraceptives were $7.8,34.9,94.9$, and 95.7 respectively (Liu Juyu 1983:22). The percentages for Red Sky women born during analogous periods-before 1926, 1927-38, and 1939-50-were 7.4, 28.6, and 78.7.

Because the Chinese fertility survey of 1982, like my own in Red Sky, was based on retrospective data, it provides a basis for comparison with urban China generally since 1950 . Figure 12 shows that, although the level of fertility has been consistently lower in Red Sky, the overall pattern has been very similar. ${ }^{8}$ A likely reason for Red Sky's lower fertility is that the fertility survey incorporated data from many smaller cities and towns where family planning has been less systematic and effective and where rural influences and traditions are likely to have been more persistent. The Chinese define an area as "urban" if it has a population of more than 2,000, at least half of which is employed in nonagricultural pursuits (Kane 1985:83). That the two curves converge after 1972 suggests that family planning efforts may have become increasingly effective in China's smaller cities and towns in recent years.

There is some evidence that fertility has recently risen in Red Sky and in China generally. The data on marital fertility in Red Sky (Figure 8) indicate such a rise since 1976. Earlier I reported that, although the marriage law revision in 1980 increased the legal age at marriage from 18 to 20 for women, administrative procedures that had formerly operated to keep marriage age well above the legal minimum were relaxed. This was partly because "of the social problems created by postponing marriage past age 23 in a society in which women are traditionally married soon after menarche and in which sexual relations among unmarried people are not socially acceptable" (Coale 1984:45). The new law was thus accompanied by a marriage boom. According to Coale:

8. "Urban" in the 1982 census referred to people living in a city or town designated urban by the State Council whether or not they were registered there and eligible for commercial grain rations. An area was designated a town if industries, commerce, and handicraft enterprises were concentrated and if the population exceeded 3,000 persons of whom 70 percent were not involved in agriculture, or if the population numbered between 2,500 and 3,000 with over 85 percent nonagricultural. Places with populations over 100,000 were designated cities, as were places with smaller populations that were provincial capitals or centers of commerce and heavy industry (Goldstein 1985:6-17). Altogether, 2,664 towns and 236 cities were designated "urban" for census purposes. The 1982 fertility survey used a more restricted definition that required entitlement to commercial grain rations as well as urban residence (Banister 1984:264-65; Goldstein 1985:10-11). This difference can be of considerable importance in a consideration of rural-urban differences. In this particular case, however, although I have used the census definition, the results are nonetheless comparable to those of the fertility survey because no residents of Red Sky were without urban registration and entitlement to commercial grain rations. 


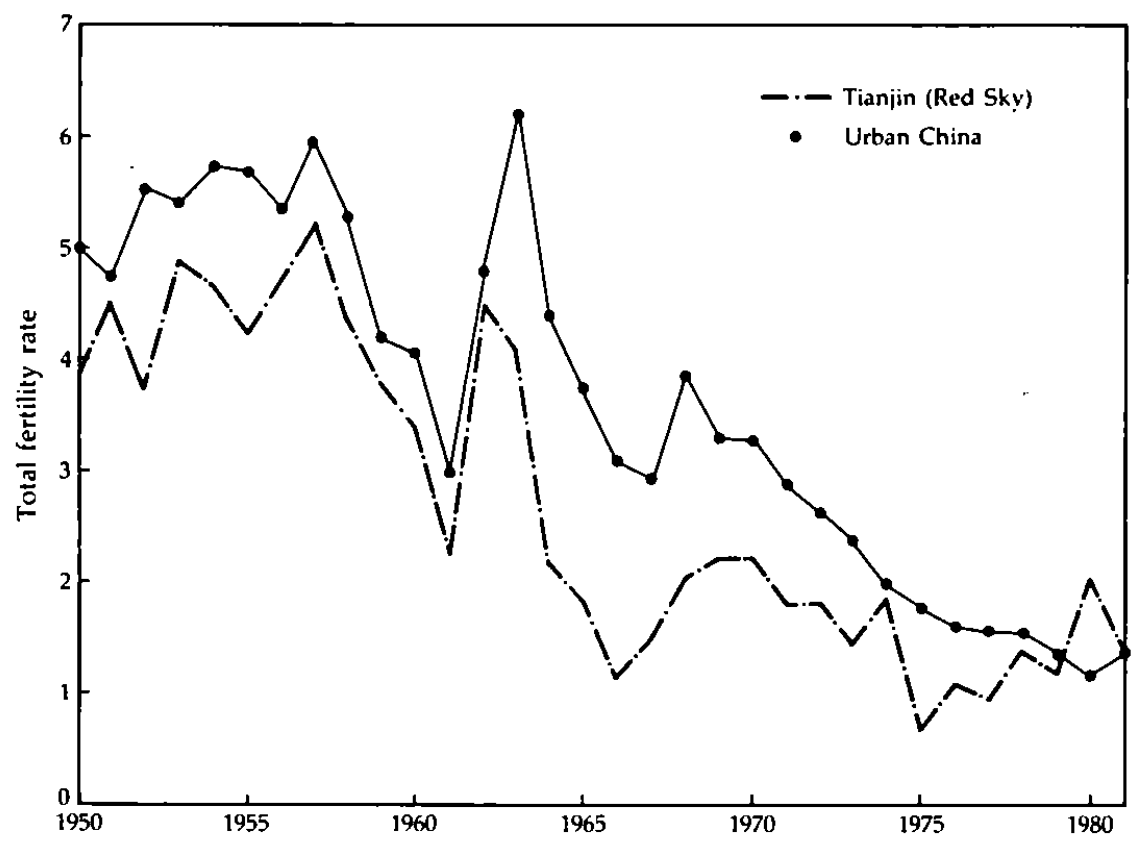

Figure 12. Total fertility: Red Sky and urban China, 1950-81

... the increase in mean age at marriage that was the principal source of low total marriage rates also produced a reduced number of women in the early durations of marriage. The cessation and slight reversal of the increase in age at marriage, plus the marriage boom associated with the new marriage law of 1980 , produced a phenomenal increase in the total marriage rate and a commensurate increase in the number of marriages of short duration. A consequence is that a rise in overall fertility by 18 percent (from a TFR of 2.41 in 1979 to one of 2.85 in 1982) would have occurred with constant fertility by duration of marriage (Coale 1984:54).

Although Red Sky residents also noted the relaxation of administrative pressures for late marriage, the mean age at marriage for women has not declined. In December 1979 a proclamation on late marriage and planned birth issued by the Tianjin Municipal Revolutionary Committee was put into effect. It established "optimal" marriage ages of 25 for urban men and women, or if one partner was over 28 , the other could be 24 . The proportion of women actually marrying below age 27 was slightly (but not significantly) lower for women married during 1979-81 than for those married during 1970-78 (62 percent compared with 69 percent). Another aspect of the relaxation of administrative controls on marriage may have, in this 
particular case at least, contributed to a rise in marital fertility. Residents indicate that pressures to delay the birth of their first child have also been reduced since 1976. Authorities reportedly now believe that "getting in line" for permission to have a child is less urgent precisely because marriage continues to be late and because the proportion of couples having a second child has dramatically diminished. It is felt that, under such circumstances, allowing an earlier first birth does not adversely affect overall family planning goals and is better for the health of mother and infant. This softening of the spacing requirement may well have continued to the short first-birth interval of women born after 1950 noted earlier.

In general, family limitation has been more effective in China's cities than in the rural areas, for important economic and psychological reasons (Coale 1984:58-62). First, family income is derived from wages, and children are not allocated employment until they are about age 18. Unlike the situation in the countryside, where children become productive much earlier, urban youngsters are an economic burden until they find work. Moreover, newly married urban couples commonly live independently and are therefore less available to help their parents. Because most urban workers now receive pensions, they are also less dependent on their children for old-age support than are their rural counterparts (see Davis-Friedmann 1985:154-57).

The prevalence of neolocal postmarital residence and the fact that women earn wages mean that parents can sometimes look to daughters as well as to sons for help. I have already observed that daughters are more likely to send money to their parents than sons, and that the amounts they send do not differ significantly from remittances sent by sons. Married daughters often visit and help with shopping, housework, cleaning, care in time of illness, and childcare. There is less pressure than in the countryside, therefore, to have some minimal number of sons. Many of the women I interviewed claimed that, in present circumstances, daughters may actually be more valuable than sons. While this may be an overstatement, there can be little doubt that daughters are more likely sources of support than ever before, whereas daughters-in-law are less dependable now than when they were economically and physically under the control of their mothersin-law. Bonds of affection and loyalty between daughters and their parents are no.longer severed at marriage.

\section{CONCLUSIONS}

After Tianjin's flood in 1939 and the two disastrous crop years that resulted from it, fertility in Red Sky began a gradual recovery. By Liberation, fertility had reached preflood and pre-Japanese levels. From 1949 fertility con- 
tinued to rise as birth intervals decreased. Fertility peaked in 1957 and then plummeted from 1959 to 1961 . A short recovery in 1962 was immediately followed by another deep drop to an unprecedented low, well below replacement levels, in 1966. From 1966 to 1970 there was a modest recovery, but only to replacement levels, and from 1970 fertility once again gradually fell below replacement level.

What accounts for these modulations? Changes occurring after Liberation might be expected to have inhibited the fertility of women in Red Sky either by increasing the costs or by decreasing the rewards of having children. As families increasingly count on income women earn outside the home, for example, the value of women's domestic work declines and the cost of having a woman remain at home to care for children increases relative to the income she might obtain by going out to work. The involvement of women in nondomestic work did increase substantially after Liberation, but fertility continued to rise until 1958. The drop in fertility that then occurred and the fertility changes that took place thereafter cannot be accounted for by shifts in the degree to which women worked outside the home.

Education became fully accessible to women after Liberation, and more time and effort are now spent preparing the occupational and economic basis of marriage. This change too might increase the cost side of whatever formula governs childbearing decisions. Not only are adults interested in taking advantage of schooling and therefore willing to delay marriage, but there are also costs involved in sending children to school. Furthermore, whatever financial contribution children might make to the domestic economy cannot begin until they have left school and have been assigned a job. Often they marry and move away shortly thereafter. Although the burden of childbearing has therefore increased and there has been a gradual and constant rise in age at marriage, the fall in fertility has not been constant or continuous.

Not only have the costs of having children increased relative to the benefits, but separation of the conjugal unit from both parental families and growing independence of the conjugal pair have reduced the effectiveness of pronatalist pressures hitherto exerted by mothers-in-law and mothers anxious to ensure support in their old age. But the crucial shift to neolocality had begun even before Liberation and, as we have seen, fertility initially rose even as women became better educated, more involved in the work force, and more independent. Whatever contribution conjugal independence and increasing self-reliance may have made to declining fertility, then, it cannot account for the overall pattern of change after 1949.

All of these changes-involvement of women in the work force, increased access to education, and the growing independence of married 
couples-should, theoretically, have conspired to produce a drop in fertility after 1949. Although a fertility decline did occur, the pattern of change suggests that fertility was profoundly affected by factors other than those outlined above. In contrast to the position taken elsewhere by Whyte and Parish (1984), who argue that many of the changes that have occurred in China since Liberation are expectable results of a more general modernization process, my view is that, as far as changes in fertility are concerned, more classical theories of "modernization" seem to have little predictive or retrodictive value. Nor can it be argued that some general "socialist" model of modernization would be any more useful. Rather, the factors most responsible for the overall pattern of fertility change since 1949 have been fundamentally political so that the pattern of fertility change has been as distinctive as China's version of socialism. It is therefore more useful to explore the relationship between the two more directly than to attempt to force a more general model on the evidence. What I am suggesting, in short, is that modernization theory and the model of demographic transition are not refined enough to anticipate the fertility transformations that occurred in Red Sky. It is more useful to begin with the demographic pattern, using it to signal potentially important economic, political, or social causes, than to begin with specific social changes, assuming that they would have a powerful effect on fertility change. In this paper I have used fertility to identify some of the social, political, and economic changes that may have been crucial. But my observations have only pointed the way to areas of ethnographic and ethnohistorical research that will be necessary to test and refine these speculations. 


$$
\text { - }
$$




\section{REFERENCES}

Arnold, Fred, Rodolfo A. Bulatao, Chalio Buripakdi, Betty Jamie Chung, James T. Fawcett, Toshio Iritani, Sung Jin Lee, and Tsong-Shien Wu

1975 The Value of Children: A Cross-National Study, Vol. 1, Introduction and Comparative Analysis. Honolulu: East-West Population Institute, EastWest Center.

Banister, Judith

1984 An analysis of recent data on the population of China. Population and Development Review 10(2):241-71.

Becker, G.S.

1960 An economic analysis of fertility. In Demographic and Economic Change in Developed Countries, pp. 209-40. Princeton, NJ: Princeton University Press.

Blake, Judith

1965 Demographic science and the redirection of population policy. In Public Health and Population Change, edited by M. Sheps and J.C. Ridley, pp. 41-69. Pittsburgh, PA: University of Pittsburgh Press.

1971 Reproductive motivation and population policy. Bioscience 21(5):215-20.

Bongaarts, John, and Susan Greenhalgh

1985 An alternative to the one-child policy in China. Population and Development Review 11(4):585-617.

Bongaarts, John, and Jane Menken

1983 The supply of children: A critical essay. In Determinants of Fertility in Developing Countries, Vol. I, edited by Rodolfo A. Bulatao and Ronald D. Lee, pp. 27-60. New York: Academic Press.

Bongaarts, John, and Robert G. Potter

1983 Fertility, Biology and Behavior: An Analysis of the Proximate Determinants. New York: Academic Press.

Caldwell, John C.

1979 Education as a factor in mortality decline: An examination of Nigerian data. Population Studies 33:395-413.

1982a The failure of theories of social and economic change to explain demographic change: Puzzles of modernization or Westernization. In Theory of Fertility Decline, edited by John C. Caldwell, pp. 269-300. New York: Academic Press. 
1982b Mass education as a determinant of the timing of fertility decline. In Theory of Fertility Decline, edited by John C. Caldwell, pp. 301-30. New York: Academic Press.

1982c Theory of Fertility Decline. New York: Academic Press.

Caldwell, John C., and Pat Caldwell

1977 The role of marital sexual abstinence in determining fertility: A study of the Yoruba in Nigeria. Population Studies 31:193-217.

Caldwell, John C., and K. Srinivasan

1984 . New data on nuptiality and fertility in China. Population and Development Review 10(1):71-79.

Chen, Pi-chao

1985 Birth control methods and organization in China. In China's OneChild Family Policy, edited by Elisabeth Croll, Delia Davin, and Penny Kane, pp. 135-48. New York: St. Martin's Press.

China Daily News

2 January 1986.

China Yearbook 1937-45

1947 New York: The MacMillan Co.

China Yearbook 1950

1950 New York: Rockport Press, Inc.

Coale, Ansley J.

1975 The demographic transition. In The Population Debate: Dimensions and Perspectives, Vol. I, pp. 347-55. New York: United Nations.

1984 Rapid Population Change in China, 1952-1982. Washington, D.C.: National Academy Press.

Cochrane, Susan H.

1979 Fertility and Education: What Do We Really Know? Baltimore, MD: The Johns Hopkins University Press.

Collver, Andrew, and E. Langlois

1962 The female labor force in metropolitan areas: An international comparison. Economic Development and Cultural Change 10(4):367-85.

Concepción, Mercedes B.

1974 Female labor force participation and fertility. Intemational Labor Review 109:503-17. 
Croll, Elisabeth

1985 The single-child family in Beijing: A first-hand report. In China's OneChild Family Policy, edited by Elisabeth Croll, Delia Davin, and Penny Kane, pp. 190-232. New York: St. Martin's Press.

Davis-Friedmann, Deborah

1985 Old age security and the one-child campaign. In China's One-Child Family Policy, edited by Elisabeth Croll, Delia Davin, and Penny Kane, pp. 149-61. New York: St. Martin's Press.

DeTray, Dennis

1976 Population growth and educational policies: An economic perspective. In Population and Development: The Search for Selective Interventions, edited by Ronald G. Ridker, pp. 182-209. Baltimore, MD: The Johns Hopkins University Press.

Easterlin, Richard A.

1973 Relative economic status and the American fertility swing. In Family Economic Behavior: Problems and Prospects, edited by E. Sheldon, pp. 170-223. Philadelphia: J.B. Lippincott.

Easterlin, Richard A., Robert A. Pollak, and Michael L. Wachter

1980 Toward a more general economic model of fertility determination: Endogenous preferences and natural fertility. In Population and Economic Change in Developing Countries, edited by Richaird A. Easterlin, pp. 81-135. Chicago: University of Chicago; Press.

Five Cities Family Research Project Group

1985 Zhonnguo Chengshi Jiating: Wu Chengshi Jiating Diaocha Baogao Ji Zeliao Hueibian [The Chinese Urban Family: Five Cities Family Survey Report and Collected Data]. Jinan: Shandong People's Publishing House.

Freedman, Ronald, D. Goldberg, and Doris Slesinger

1963 Current fertility expectations of married couples in the United States. Population Index 29:366-91.

Gamble, Sidney D.

1921 Peking: A Social Survey Conducted Under the Auspices of the Princeton University Center in China and the Peking Young Men's Christian Association. New York: Doran.

Gendell, M.

1967 The influence of family building activity on women's rate of economic activity. In Proceedings of the World Population Conference, Belgrade, 1965, Vol. 4: Migmation, Urbanization, Economic Development, pp. 285-86. New York: United Nations. 
Goldstein, Sidney

1972

The influence of labor force participation and education on fertility in Thailand. Population Studies 26:419-36.

1985 Urbanization in China: New Insights from the 1982 Census. Papers of the East-West Population Institute, No. 93. Honolulu: East-West Center.

$\mathrm{Gu}$ Xingyuan, Shu Baogang, Li Jieping, and Chi Xinju

1981 Shanghai shi jihua shengyu diaocha ji renkou yuzhe baogao (Survey report on family planning and population trends in Shanghai).

In Disanci Xuanguo Renkou Kexue Taolun Hui Lunwen Xuanji "Renkou Yenjiu" Dzengkan [Population Research Supplement, Selected Works of the Third National Demographic Conference], pp. 228-32. Shanghai: Shanghai First Medical School; Statistical, Teaching and Research Office of Social Medicine and Health; Shanghai Office of Family Planning.

Hershatter, Gail

1982 The making of the working class in Tianjin, 1900-1949. Unpublished doctoral dissertation in history. Stanford: Stanford University.

Hoffman, Lois W., and Martin L. Hoffman

1973 The value of children to parents. In Psychological Perspectives on Population, edited by James T. Fawcett, pp. 19-76. New York: Basic Books.

Hoffman, Lois W., and Frederick Wyatt

1960 Social change and motivations for having larger families: Some theoretical considerations. Merrill-Palmer Quarterly 6:235-44.

Jaffe, A.J., and K. Azumi

1960 The birth rate and cottage industries in underdeveloped countries. Economic Development and Cultural Change 9:52-63.

Kane, Penny

1985 The single-child family policy in the cities. In China's One-Child Family Policy, edited by Elisabeth Croll, Delia Davin, and Penny Kane, pp. 83-113. New York: St. Martin's Press.

Khan, M. Ali, and Ismail Sirageldin

1979 Education, income and fertility in Pakistan. Economic Development and Cultural Change 27:519-47.

Lee, H.C., and H. Cho

1976

Fertility and women's labor force participation in Korea. In Recent Empirical Findings on Fertility: Korea, Nigeria, Tunisia, Venezuela, Philippines. Occasional Monograph Series, No. 7. Washington, D.C.: Smithsonian Institution. 
Lesthaeghe, Ron, Hilary J. Page, and O. Adegobla

1981 Child-spacing and fertility in Lagos. In Child-Spacing in Tropical Africa: Traditions and Change, edited by Hilary J. Page and Ron Lesthaeghe. New York: Academic Press.

LeVine, Robert A.

1980 Influences of women's schooling on maternal behavior in the Third World. Comparative Education Review 24(2, Part 2):S78-S105.

Li Chengrui

1985 Economic reform brings better life. Beijing Review 29(July 22):15-29.

Li Hongfa

1981 Workers' living standards in Tianjin. China Reconstructs (July):45-46.

Lieberthal, Kenneth G.

1980 Revolution and Tradition in Tientsin, 1949-1952. Stanford: Stanford University Press.

Lin Sung-ho

1928 Factory Workers in Tangku. Peking: China Foundation.

Liu Chunmei and Li Zhu

1984 Sex structure of population in China. In Analysis on China's National One-per-Thousand-Population Fertility Sampling Survey, Pp. 153-58. Beijing: China Population Information Center.

Liu Juyu

1983 Beijing shi Xicheng qu funu butong shiqi shengyu zhuangkuang huigu xing diaocha [Retrospective survey of fertility during different periods in Xicheng district, Peking]. Renkou Yu Jingii [Population and Economy] 1:18-23.

Lyle, Katherine

1980 Report from China: Planned birth in Tianjin. China Quarterly 83:551-67.

Mao Tse-tung

1954 Report of an investigation into the peasant movement in Hunan. In Mao-Tse Tung: Selected Works, pp. 21-59. New York: International Publishers.

Mason, Karen $\mathrm{O}$.

1974 Women's Labor Force Participation and Fertility. Research Triangle Park, NC: Research Triangle Institute. 
McClelland, Gary H.

1983 - Family-size desires as measures of demand. In Determinants of Fertility in Developing Countries, Vol. I, edited by Rodolfo A. Bulatao and Ronald D. Lee, pp. 288-343. New York: Academic Press.

Michael, Robert T.

1973 Education and the derived demand for children. Journal of Political Economy 81(2, Part II):S128-S164.

Mueller, Eva

1972 . Economic motivations for family limitation. Demography 26(3):383-403.

Nag, Moni

1983 The impact of sociocultural factors on breastfeeding and sexual behavior. In Determinants of Fertility in Developing Countries, Vol I, edited by Rodolfo A. Bulatao and Ronald D. Lee, Pp. 163-98. New York: Academic Press.

Notestein, Frank

1953 Economic problems of population change. In Proceedings of the Eighth International Conference of Agri-Economists. Oxford: Oxford University Press.

Pao Chiao-ming and He Tz'u-ch'iang

1960 Tientsin. U.S. Government Translation. Originally published in Moscow.

Pasternak, Burton, and Wang Ching

1985 Breastfeeding decline in urban China: An exploratory study. Human Ecology 13:433-66.

People's Daily [Renmin Ribao]

7 March 1983.

Pratt, L., and P. Whelpton

1956 Extra-familial participation of wives in relation to interest in and liking for children, fertility planning and actual and desired family size. Milbank Memorial Fund Quarterly 34:44-78.

Ridley, Jeanne C.

1959 Number of children expected in relation to non-familial activities of the wife. Milbank Memorial Fund Quarterly 37:277-96

Schultz, Theodore W.

1973 The value of children: An economic perspective. Journal of Political Economy 81(2, Part II):S2-S13. 
Shryock, Henry S., Jacob S. Siegel, et al.

1975 The Methods and Materials of Demography. Washington, D.C.: U.S. Bureau of the Census.

Speare, Alden, Jr., Mary C. Speare, and Hui-Sheng Lin

1973 Urbanization, non-familial work, education and fertility in Taiwan. Population Studies 27:323-34.

State Council Census Office

1983 Disan Ci Quanquo Renkou Pucha Shougong Huizong Ziliao Huibian [Collection of Manually Tabulated Data from the Third National Census, Vols. 2, 5, 6]. Beijing.

State Statistical Bureau

1983 Ten Percent Sampling Tabulation on the 1982 Population Census of the People's Republic of China. Beijing: China Statistical Publishing House.

Stycos, J. Mayone

1965 Female employment and fertility in Lima, Peru. Milbank Memorial Fund Quarterly 43:42-54.

Stycos, J. Mayone, and Robert H. Weller

1967 Female working roles and fertility. Demography 4:210-17.

Tianjin Municipal Statistics Bureau

1948 Tianjin Shi Juyao Tongji Zeliao Shouce [Handbook of Essential Tientsin Statistical Data].

Tianjin Municipality Executive Office

1939 Tianjin Tebye Shi Xingjeng Zueiyao [Essential Administrative Data for Tientsin Special City].

Tien, H. Yuan

1985 Provincial fertility trends and patterns. In China's One-Child Family Policy, edited by Elisabeth Croll, Delia Davin, and Penny Kane, pp. 114-34. New York: St. Martin's Press.

United Nations, Department of International Economic and Social Affairs

1983 Relationships Between Fertility and Education: A Comparative Analysis of World Fertility Survey Data for Twenty-Two Developing Countries. New York.

Weller, Robert $\mathrm{H}$.

1968. The employment of wives, dominance and fertility. Joumal of Marriage and the Family 30(3):437-42. 
Westoff, Charles F., Robert G. Potter, and Philip C. Sagori

1963 The Third Child. Princeton: Princeton University Press.

Whyte, Martin K., and William L. Parish

1984 Urban Life in Contemporary China. Chicago: University of Chicago Press.

Willis, Robert J.

1973 A new approach to the economic theory of fertility behavior. Joumal of Political Economy, Supplement:S14-S69.

Wolf, Arthur, and Chieh-shan Huang

1980 Marriage and Adoption in China, 1845-1945. Stanford: Stanford University Press.

Ye Yanru

1983 Beijing shi Haidian qu shengyu shi diaocha zhong kandao de jige wenti [Some problems arising from the study of fertility history of women in Haidian district, Peking]. Renkou Yu jingji [Population and Economy] 1:43-53. 
60-E The changing value of children in Turkey, by Cigdem Kagitcibasi, June 1982, viii + 100 pp.

81 Labor markets, urban systems, and the urbanization process in Southeast Asian countries, by Terence G. McGee, July 1982, vi + 28 pp.

82 Ethnicity, birthplace, and achievement: the changing Hawaii mosaic, by Paul Wright and Robert W. Gardner, February 1983, vi +41 pp.

83 Population distribution policies in Asia and the Pacific: current status and future prospects, by Roland J. Fuchs, February 1983, viii + 40 pp.

84 Circulation and interpersonal networks linking rural and urban areas: the case of Roi-et, Northeastern Thailand, by Paul Lightfoot, Theodore Fuller, and Peerasit Kamnuansilpa, March 1983, vi + 46 pp.

85 Development perspectives and populaxion change, by Ozzie G. Simmons, April 1983, $\mathrm{vi}+41 \mathrm{pp}$.

86 The effects of induced abortion on subsequent reproductive function and pregnancy outcome: Hawaii, by Chin Sik Chung and Patricia G. Steinhoff in collaboration with Roy G. Smith and Ming-Pi Mi, June 1983, xii + 144 pp.

60-F Influences on childbearing intentions across the fertility career: demographic and socioeconomic factors and the value of children, by Rodolfo $\mathrm{A}$. Bulatao and James $\mathrm{T}$. Fawcett, June $1983, x+152$ pp

Population mobility and wealth transfers in Indonesia and other Third World societies, by Graeme J. Hugo, July 1983, vi +50 pp

88 Structural change and prospects for urbanization in Asian countries, by Gavin W. Jones, August 1983, vi $+46 \mathrm{pp}$

89 Urban growth and local taxes in less developed countries, by Roy Bahl, Daniel Holland, and Johannes Linn, September 1983, vi +33 pp.

90 A false fertility transition: the case of American blacks, by Paul Wright and Peter Pirie, February 1984, viii +81 pp

60-G The old-age economic security value of children in the Philippines and Taiwan, by Susan De Vos, March 1984, viii + 72 pp.

91 A profile of Hawaii's elderly population, by Eleanor C Nordyke, Richard K.C. Lee, and Robert W. Gardner, August 1984, viii +39 pp.

92 City characteristics, migration, and urban development policies in India, by Mahendra K. Premi with Judith Ann L. Tom, June 1985, viii + 127 pp

93 Urbanization in China: new insights from the 1982 Census, by Sidney Goldstein, July 1985, vi +73 Pp

94 Comparison of fertility trends estimated alternatively from birth histories and own children, by Robert D. Retherford and Iqbal Alam, July 1985, viii + 39 pp.

95 Population mobility in the People's Republic of China, by Sidney Goldstein and Alice Goldstein, October 1985, vi $+46 \mathrm{pp}$

96 Factors in the achievement of below-replacement fertility in Chiang Mai, Thailand, by Tieng Pardthaisong, March 1986, viii +46 pp.

97 The Population of Burma: An analysis of the 1973 Census, by M. Ismael Khin Maung, April 1986, viii + 32 Pp.

98 Population aging in Australia: Implications for social and economic policy, by Graeme Hugo, April 1986, viii +47 pp. 
THE EAST-WEST CENTER is a public, nonprofit educational institution with an international board of governors. Some 2,000 research fellows, graduate students, and professionals in business and government each year work with the Center's international staff in cooperative study, training, and research. They examine major issues related to population, resources and development, the environment, culture, and communication in Asia, the Pacific, and the United States. The Center was established in 1960 by the United States Congress, which provides principal funding. Support also comes from more than 20 Asian and Pacific governments, as well as private agencies and corporations.

Situated on 21 acres adjacent to the University of Hawaii's Manoa Campus, the Center's facilities include a 300 -room office building housing research and administrative offices for an international staff of 250 , three residence halls for participants, and a conference center with meeting rooms equipped to provide simultaneous translation and a complete range of audiovisual services.

THE EAST-WEST POPULATION INSTITUTE, established as a unit of the EastWest Center in 1969, carries out multidisciplinary research, training, and related activities in the field of population, placing emphasis on economic, social, psychological, and environmental aspects of population problems in Asia, the Pacific, and the United States. 